\title{
An Adaptive Approach to Forecasting Three Key Macroeconomic Variables for Transitional China
}

\author{
Linlin Niu* \\ Xiu $\mathrm{Xu}^{*}$ \\ Ying Chen**
}

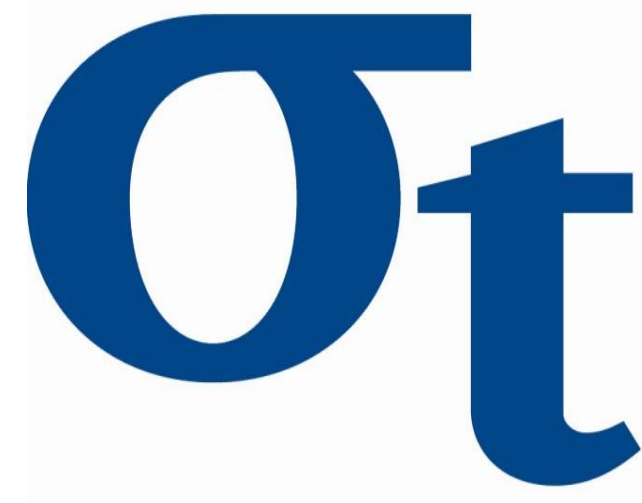

* Xiamen University, People's Republic of China

This research was supported by the Deutsche Forschungsgemeinschaft through the SFB 649 "Economic Risk". 


\title{
An Adaptive Approach to Forecasting Three Key Macroeconomic Variables for Transitional China
}

\author{
Linlin $\mathrm{Niu}^{a, b, c *} \quad \mathrm{Xiu} \mathrm{Xu}^{a \dagger}$ Ying Chen ${ }^{d}$ \\ ${ }^{a}$ Wang Yanan Institute for Studies in Economics (WISE), Xiamen University, China \\ ${ }^{b}$ Bank of Finland, Institute for Economies in Transition (BOFIT) \\ ${ }^{c}$ Key Laboratory of Econometrics (Xiamen University), Ministry of Education, China \\ ${ }^{d}$ Department of Statistics \& Applied Probability, National University of Singapore
}

\begin{abstract}
We propose the use of a local autoregressive (LAR) model for adaptive estimation and forecasting of three of China's key macroeconomic variables: GDP growth, inflation and the 7-day interbank lending rate. The approach takes into account possible structural changes in the data-generating process to select a local homogeneous interval for model estimation, and is particularly well-suited to a transition economy experiencing ongoing shifts in policy and structural adjustment. Our results indicate that the proposed method outperforms alternative models and forecast methods, especially for forecast horizons of 3 to 12 months. Our 1-quarter ahead adaptive forecasts even match the performance of the well-known CMRC Langrun survey forecast. The selected homogeneous intervals indicate gradual changes in growth of industrial production driven by constant evolution of the real economy in China, as well as abrupt changes in interestrate and inflation dynamics that capture monetary policy shifts.
\end{abstract}

Keywords: Chinese economy, local parametric models, forecasting

JEL Classification: E43, E47

\footnotetext{
${ }^{*}$ Linlin Niu acknowledges the support of the Natural Science Foundation of China (Grant No. 70903053 and Grant No. 71273007), and thanks BOFIT Visiting Researcher Programme for hospitality during her research stay at BOFIT.

${ }^{\dagger}$ Corresponding author. Xiu Xu, Rm A306, Economics Building, Xiamen University, Xiamen, 361005, Fujian, China. Email: xiu.xu@stu.xmu.edu.cn. Phone: +86-592-2182839. Fax: +86-592-2187708. Xiu Xu thanks the support by the Deutsche Forschungsgemeinschaft through the International Research Training Group IRTG 1792 "High Dimensional Non Stationary Time Series" and the SFB 649 Economic Risk.
} 


\section{Introduction}

A large body of literature focuses on forecasting important macroeconomic variables such as inflation rate and GDP growth, yet accurate prediction of these variables remains elusive for economists and policymakers (Bräuning and Koopman, 2013; Clements and Hendry, 2008; De Gooijer and Hyndman, 2006). One of the biggest challenges lies in the irregular, unanticipated, and sometimes large, shifts in economic activities that lead to parameter instabilities in parameterized models (D'Agostino et al., 2013; Stock and Watson, 1999, 2007). As a result, the forecasting performance of econometric models may vary dramatically across different sample periods (Rossi and Sekhposyan, 2010). The task of accurately forecasting major macroeconomic variables become even more daunting for transition economies such as China, Russia and countries in eastern Europe as they suffer from limited effective data length compared to developed economies, as well as frequent structural changes and evolving policies.

China has seen several decades of rapid economic growth and remarkable economic achievements since the launch of its reforms in 1978. GDP growth averaged 9.8\% a year from 1978 to 2013, and China surpassed Japan as the world's second largest economy in 2009. This extraordinary performance reflects two simultaneous trends: China's gradual transition from a planned economy to its current socialist market model, and the active adoption of modern technology and management practices. During its transition process, China has experienced major policy regime shifts and vast structural reforms. Notable reforms include the agricultural reform that introduced household responsibility system in 1981; the reform of state-owned enterprises (SOEs) in the 1980s; decentralization of decision-making and the rise of township enterprises in the mid-1980s; the marketization of prices in 1992; the fiscal and tax system reform in 1994 to broaden the tax base and decentralize the tax collection power; the financial system reform in 1999; entry into the WTO in 2002; and the reform in exchange-rate regime in 2005 (Naughton, 2007; Lin, 2013; Chow, 2015). Such policy adjustments can affect economic structures, pricing mechanisms, degrees of market competition and the decision-making powers of agents in ways that impact aggregate economic variables such as GDP growth, the inflation rate and key interest rates. Thus, the dynamics of these variables in a transition economy context need to reflect these structural changes to achieve a modicum of forecasting accuracy.

The literature provides many fruitful studies in forecasting macroeconomic variables, ranging from parsimonious time-series models and macro-theoretical based models such as the Philips curve model to structural VAR and factor-augmented VAR models (Stock and Watson, 1999, 2002a,b; Forni et al., 2000, 2003; Bai and Ng, 2002, 2008). To address the issue of parameter instability, many models include features of long memory or structural breaks (Clements and Hendry, 1996; Banerjee et al., 2008; Stock and Watson, 2009; Clark 
and McCracken, 2010; Geweke and Jiang, 2011; D'Agostino et al., 2013). Even so, complex econometric models often fail to outperform simple time-series models or forecasts based on survey data (Ang et al., 2007; Stock and Watson, 2008; Belmonte and Koop, 2014). The factor-augmented VAR model, for example, hinges on the effective selection of factors and tends to perform poorly in out-of-sample forecasting due to potential structural changes of the factors. Predicting local shifts in factors can also present computationally non-trivial challenges (Castle et al., 2013).

Moreover, most of the above-mentioned methodological research work on predicting macroeconomic time series focuses on developed countries. Existing macroeconomic forecasts for developing countries, especially transition economies, tend to be empirical applications and comparisons of the aforementioned forecast models and approaches. For example, Krkoska and Teksoz (2007) make a comprehensive analysis of the forecast accuracy of output growth for transition countries in central and eastern Europe and former Soviet Republics based on the performance of forecasts produced by the European Bank for Reconstruction and Development (EBRD). Ahumada and Garegnani (2012) estimate Argentinian money demand with an equilibrium-correction model of monetary aggregate M2 and compare the performance of the model with alternative forecasting approaches, including VAR, naive models and pooling of different forecasts. Notably, studies of systematic forecasting in transition economies largely overlook transition effects.

Forecasting macroeconomic indicators of transition economies has two notable features. First, structural changes due to policy and regime shifts occur much more often than in developed economies. Second, available data tend to be far more limited and of poorer quality than in developed economies. This paper takes these two features into consideration by incorporating an adaptive approach for estimating and forecasting three key macroeconomic variables for China with a local autoregressive (LAR) model.

Chen, Härdle and Pigorsch (2010) initially propose a LAR model to forecast realized volatilities in order to identify typical long-memory patterns of financial time series. Since parameter instability of stationary processes can produce spurious long-memory phenomena, the authors adopt a strategy of nesting local homogenous intervals with relatively stable parameters into a global process. Through Monte Carlo experiments and empirical out-ofsample forecasting for the potentially nonstationary time series, their LAR method beats popular alternative models when dynamic selection of the homogeneous sample interval is used with a parsimonious local AR(1) model. Chen and Niu (2014) further apply the local adaptive approach to forecast the term structure of US interest rates. Their method substantially outperforms alternative term-structure methods in forecasts with 3 - to 12 month horizons. The approach is shown to capture structural changes of the time series quite well, and commonly identified interval endings are in line with major policy changes 
or economic recessions.

Given the above-mentioned feature of transition economies, the LAR model appears particularly suitable for forecasting key macroeconomic variables in situations of limited sample length or vulnerability to structural breaks. Recent successful applications of the adaptive approach include Härdle et al. (2014a) and Härdle et al. (2014b) in forecasting trading volumes and order flow in financial markets.

Based on adaptively identified homogeneous intervals, we directly utilize a parsimonious LAR(1) model to forecast China's macroeconomic variables. Our three selected variables are the growth rate of industrial production (IP growth) as a proxy for real GDP growth, the CPI inflation rate as a representative for nominal variables, and the 7-day China Interbank Offered Rate (Chibor, i.e. National Interbank Offered Rate) as a money market indicator. For forecast comparison, we choose popular forecast models with predetermined estimation windows as alternatives. For inflation, we follow Ang et al. (2007), employing a Philips curve model, a time-series AR model, an interest-rate term-structure model and a combined model. For IP growth, we draw on the idea of selecting alternative models suggested by Stock and Watson (2002a), choosing as our alternative models an AR model, macroeconomic models with various factors, a random-walk model and a combined model. For interest rate, we choose AR and random-walk models as alternatives.

The literature repeatedly points to the difficulty of beating survey forecasts (e.g. Ang et al., 2007; Belmonte and Koop, 2014), so we compare our forecast results against the well-recognized China Macroeconomic Research Center (CMRC) Langrun survey forecast.

Our LAR model substantially outperforms alternative models with predetermined regression windows in 3- to 12-month ahead forecasts. For example, the forecast root mean squared errors (RMSE) of the 12-month ahead LAR forecast has been reduced by about $30 \%$ compared to alternative models. Our 1-quarter ahead LAR forecasts are as good as CMRC survey forecasts.

The LAR identified homogeneous intervals further provide useful information on monitoring and understanding China's economic dynamics in real time. We find from the identified homogenous intervals several abrupt changes in inflation and interest rate that are in line with major reforms of monetary policy and institutions. For IP growth, in contrast, only gradual changes in homogenous intervals are detected. This likely reflects gradual transition of the real economy, echoing the immensity and scope of China's economic reforms.

The rest of the paper is organized as follows. Section 2 describes the adaptive model. Section 3 presents our data, the forecast procedure and alternative models for comparison. Section 4 presents the forecast results and comparison with detailed discussion. Section 5 concludes. 


\section{LAR-based adaptive modeling and forecasting}

We follow Chen, Härdle and Pigorsch (2010) to model each of the macroeconomic time series as an LAR(1) model. The time series in an identified homogenous interval can be modeled locally as a typical AR model with approximately constant parameters. The LAR treats the parameters globally in a time-varying manner. Chen, Härdle and Pigorsch (2010) show that a simple LAR model can outperform GARCH models and other popular volatility models when applied to forecasting realized volatility. Chen and Niu (2014) extend their local autoregressive model to incorporate exogenous variables (LARX model). The LARX model effectively forecasts yield factors and outperforms typical yield curve models substantially over 3- to 12-month forecast horizons.

Here, we implement a LAR estimation and forecast for three representative time series of Chinese macroeconomic variables. Although potential information from other variables can be used to enhance the forecast performance as in a LARX model, our focus is on demonstrating that an adaptive forecast with a simple model can improve substantially upon conventional models that rely on predetermined estimation windows, and that the by-product of the identified homogenous interval is useful in monitoring and understanding the pattern of structural changes in selected macroeconomic variables.

\section{$2.1 \quad$ LAR model}

This subsection gives a simplified, self-contained illustration of the LAR model estimation procedure. For further insight, Chen and Niu (2014) provide a detailed elaboration on technical calibration of critical values for the test procedure. We rely on properties and robustness of the local model studied with Monte Carlo simulations in Chen, Härdle and Pigorsch (2010).

\subsubsection{LAR model and estimator}

We model the variable using a simple LAR(1) that defines the data-generating process as an autoregressive process with one lag. Unlike a traditional $\mathrm{AR}(1)$ model, the parameter set is indexed to the local time $t$ when the model is estimated with data up to $t$. Denoting the parameter set as $\theta_{t}=\left(\theta_{0 t}, \theta_{1 t}, \sigma_{t}\right)^{\top}$, the model is:

$$
y_{t}=\theta_{0 t}+\theta_{1 t} y_{t-1}+\mu_{t}, \quad \mu_{t} \sim N\left(0, \sigma_{t}^{2}\right) .
$$

The time-varying parameter set indicates that the model recognizes possible parameter changes in the data-generating process. Additionally, the model allows for the existence and identification of a local interval of length $m_{t},\left[t-m_{t}+1, t\right]$, over which the parameter $\theta_{t}$ 
stays approximately constant, i.e. locally homogenous, so that the process can reasonably be described by a traditional autoregressive model.

For a specified interval, the (quasi) maximum likelihood estimation can be implemented to obtain the local maximum likelihood estimator $\tilde{\theta}_{t}$, which is defined as:

$$
\begin{aligned}
\tilde{\theta}_{t} & =\arg \max _{\theta_{t} \in \Theta} L\left(y ; I_{t}, \theta_{t}\right) \\
& =\arg \max _{\theta_{t} \in \Theta}\left\{-\left(m_{t}-1\right) \log \sigma_{t}-\frac{1}{2 \sigma_{t}^{2}} \sum_{s=t-m_{t}+2}^{t}\left(y_{s}-\theta_{0 t}-\theta_{1 t} y_{s-1}\right)^{2}\right\},
\end{aligned}
$$

where $\Theta$ is the parameter space and $L\left(y ; I_{t}, \theta_{t}\right)$ is the local log-likelihood function.

\subsubsection{Testing procedure for homogeneous intervals}

The key issue in the LAR modeling is a backward testing procedure to identify the longest possible homogeneous interval among various possible intervals up to time $t$. To reduce the computational burden, at any particular time point $t$, we divide the sample with discrete increments of $M$ periods $(M>1)$ between any two adjacent sub-samples to obtain $K_{t}$ candidate sub-samples,

$$
I_{t}^{(1)}, \cdots, I_{t}^{(K)} \text { with } I_{t}^{(1)} \subset \cdots \subset I_{t}^{(K)} .
$$

$I_{t}^{(1)}$ is the shortest sub-sample and should be reasonably fit by an $\mathrm{AR}(1)$ model with constant parameters.

To start the testing procedure, an underlying assumption is that $I_{t}^{(1)}$ is locally homogeneous. For a specific interval $I_{t}^{(k)}$, the maximum likelihood (ML) estimator is denoted as $\tilde{\theta}_{t}^{(k)}$ and the local homogeneous estimator is denoted as $\hat{\theta}_{t}^{(k)}$. For the first interval $I_{t}^{(1)}$, we assume $\hat{\theta}_{s}^{(1)}=\tilde{\theta}_{s}^{(1)}$ by default. For the subsequent intervals, we first obtain $\tilde{\theta}_{t}^{(k)}$ from the maximum likelihood estimation, and then determine whether to accept it as the local homogeneous estimator $\hat{\theta}_{t}^{(k)}$ with a likelihood ratio test. The test statistic is

$$
T_{t}^{(k)}=\left|L\left(I_{t}^{(k)}, \tilde{\theta}_{t}^{(k)}\right)-L\left(I_{t}^{(k)}, \hat{\theta}_{t}^{(k-1)}\right)\right|^{1 / 2}, \quad k=2, \cdots, K
$$

where $L\left(I_{t}^{(k)}, \tilde{\theta}_{t}^{(k)}\right)=\max _{\theta_{t} \in \Theta} L\left(y ; I_{t}^{(k)}, \theta_{t}\right)$ denotes the fitted likelihood under hypothetical homogeneity and $L\left(I_{t}^{(k)}, \hat{\theta}_{t}^{(k-1)}\right)=L\left(y ; I_{t}^{(k)}, \hat{\theta}_{t}^{(k-1)}\right)$ refers to the likelihood in the current testing sub-sample assuming the parameter estimate from the previously accepted local homogeneous interval. The test statistic measures the difference between these two estimates. If $I_{t}^{(k)}$ is homogenous, the difference will be due to sampling randomness. If parameter changes occur between $I_{t}^{(k-1)}$ and $I_{t}^{(k)}$, the difference should be relatively large. A set of critical values $\zeta_{1}, \cdots, \zeta_{K}$ will be used to test the differences. If $T_{s}^{(k)} \leq \zeta_{k}$, we accept the cur- 
rent sub-sample $I_{t}^{(k)}$ as being homogeneous and update the adaptive estimator $\hat{\theta}_{t}^{(k)}=\tilde{\theta}_{t}^{(k)}$. If $T_{t}^{(k)}>\zeta_{k}$, it indicates that the model significantly changes, and the testing procedure ends here and the latest accepted sub-sample $I_{t}^{(k-1)}$ is selected, such that $\hat{\theta}_{t}^{(k)}=\hat{\theta}_{t}^{(k-1)}=\tilde{\theta}_{t}^{(k-1)}$. For $\ell \geq k$, we have $\hat{\theta}_{s}^{(\ell)}=\tilde{\theta}_{s}^{(k-1)}$, meaning that the adaptive estimator for even longer sub-sample at time $t$ is the ML estimate over the identified longest sub-sample of local homogeneity. The procedure ends if a significant change is found or the longest sub-sample, $I_{t}^{(K)}$, is reached under local homogeneity. The critical values are calibrated empirically with Monte Carlo experiments using an initial training sample of the data. The computing procedure and robustness study have been illustrated in details in Chen, Härdle and Pigorsch (2010) and Chen and Niu (2014).

\section{$2.2 \quad$ Real-time estimation and forecast}

Following the test and estimation procedure described above, we estimate the LAR(1) model for each variable from a selected initial time of estimation, and then forecast the variable $h$-step ahead assuming the parameters keep homogeneity over the forecast horizons. The estimation and forecast moves forward one period at a time until the end of the entire sample is reached.

For a specific forecast horizon $h$, we follow a direct forecast approach that is simple to implement and robust for possibly mis-specified models. The LAR(1) model for horizon $h$ is specified as

$$
y_{t}=\theta_{0 t}+\theta_{1 t} y_{t-h}+\mu_{t}, \quad \mu_{t} \sim N\left(0, \sigma_{t}^{2}\right) .
$$

Hence, at time $t$, the LAR(1) model for different forecast horizons may have different sets of parameter estimates and correspondingly identified homogenous intervals.

\section{Data and out-of-sample forecasts with the LAR model}

This section introduces the macroeconomic variables to be predicted, the forecast procedure and measures of comparison with alternative models.

\subsection{Data}

Monthly data obtained from the CEIC China Economic and Industry Database cover the CPI inflation rate and the year-on-year growth of industrial production (IP growth) for the periods 1992:1-2014:3 (inflation) and 1995:1-2014:3 (IP growth). We use the weighted average of the 7-day Chibor taken from the closing interest rate of the week's final trading day from January 2001 to March 2014, which gives a total of 682 data points. It is worth mentioning that there are other interest rate candidates, such as the Shanghai Interbank 
Offer Rate (Shibor), which is officially launched from January 2007. Although Shibor is the interbank quote-based average rate while Chibor is the weighted average of the daily transaction rate at the end of each business trading day, both follow each other very closely and jointly play crucial roles as the basic interest rates in China. Considering the sample length and the consistency involved in comparison with the term structure interest models, we uniformly choose Chibor in our paper.

[Figure 1. Plot of the three macroeconomic variables]

Table 1 presents the simple statistics for the three time series. All three time series exhibit high persistence that is easily visualized from the autocorrelation functions in Figure 2 , where the autocorrelations slowly decay. This feature indicates that either the series possess relatively long memory or there are structural changes driving spurious persistence. The interest-rate series presents clustering of volatility and jumps in the dynamics that imply changing volatility in innovation. This evidence provides the justification for our application of an adaptive approach that features a globally changing, locally stationary data-generating process.

[Table 1. Statistics of the three macroeconomic variables]

[Figure 2. Autocorrelation functions of the three variables]

\subsection{LAR forecast procedure}

Due to data availability, the three macroeconomic time series have different sample periods and frequencies. Thus for each time $t$ estimation and its out-of-sample forecast, we set the maximum length of interval $I_{t}^{(K)}$ to $120+h$ periods for all variables ( $h$ denotes the forecast horizon). To reduce the computational burden when identifying the homogenous interval at time $t$, we use a universal set of sub-samples with $K=20$ and $M=6$ at each time point, starting with the shortest sub-sample covering the most recent six lag periods, setting the interval between two adjacent sub-samples to six periods, and ending with the longest sub-sample of $120+h$ periods. Once an optimal sub-sample is selected against the next longer sub-sample, the parameter change is understood to have taken place sometime within the six periods in between. In doing so, we trade off precision in break identification for computational efficiency. Precise identification of the breaking point is not a major concern, however, since our primary goal is to estimate from the identified sample with relatively 
homogeneous parameters. Also, as many changes occur smoothly, point identification of breaks need not be precise or even necessary.

The resulting initial samples for a specific forecast horizon and the forecast comparison periods are summarized in Table 2. For monthly data of inflation and IP growth, we make out-of-sample 1-, 3-, 6-, 9- and 12-month ahead forecasts, and then move forward one month at a time to forecast at these five horizons until we reach the end of the full sample. For the weekly 7-day interbank offered rate, the first sample for estimation uses data up to end 2005 for 1-, 4-, 12-, and 24-week ahead forecasts. Then we move forward one week at a time to forecast at these four horizons until we reach the end of the full sample.

[Table 2. Initial samples of estimation and periods of forecast comparison]

\subsection{Alternative models for comparison}

For comparison, we choose popular forecast models for each macroeconomic variable. The choice of regression windows follow rule of thumb, either using a rolling window of 60 or 120 periods, or using a recursive window incorporating an increasing number of past observations as the forecast moves forward. A recursive window approach is preferred if the sample has no changing parameters and the extended sample length increases information efficiency. A rolling window approach addresses the balance of information efficiency versus possible breaks and resulting parameter uncertainty. In both cases, however, the choice of window length is predetermined and not selected in a systematic, data-driven manner. Using the direct forecast approach as for the $h$-step ahead forecast of LAR(1) in equation (3), we also specify the alternative models for $h$-step ahead forecast as a generalized 1 -step ahead forecast by lagging the predetermined dependent variables $h$-step backward.

In addition to model comparison, we also use the CMRC Langrun survey forecast as an alternative. The predictive power of the Langrun survey forecast is reputed to be unbeatable as it combines the outlooks of forecast institutions in possession of rich information and using sophisticated forecast methods. The Langrun survey was initiated in July 2005 by the China Center for Economic Research (CCER) of Peking University. After the official release of the previous quarter's data, the CMRC invites about two dozen institutions to predict the major macroeconomic variables for the next quarter, including GDP growth, CPI, industrial production growth, interest rates and exchange rates. The resulting CMRC Langrun forecast provides two measures: a simple average of institutional forecasts and a weighted average based on the historical forecast accuracy of each participating institution.

We assess how our LAR(1) model performs compared to the alternative models with various predetermined window length strategies and the Langrun forecast. We denote IP 
growth, CPI inflation rate and the 7 -day Chibor at time $t$ as $y_{t}, \pi_{t}$ and $r_{t}$, respectively. The involved data in the alternative models, as will be mentioned in the following, are summarized in Table 3. Due to data availability, the intervals of data varies. This occasionally binds our choices of alternative window length selection in forecast comparison.

[Table 3. Summary of involved data in alternative models]

\subsubsection{Alternative forecasts for IP growth}

1. Time-series model of AR(1). Using a direct forecast approach as in the $h$-step ahead forecast of $\operatorname{LAR}(1)$ in equation (3), the $\mathrm{AR}(1)$ model for $h$-step ahead IP growth forecast is

$$
y_{t}=\theta_{0}+\theta_{1} y_{t-h}+\varepsilon_{t}, \varepsilon_{t} \sim N\left(0, \sigma_{t}^{2}\right),
$$

and its corresponding time- $t$ forecast is

$$
\widehat{y}_{t+h / t}=\widehat{\theta}_{0}+\widehat{\theta}_{1} y_{t}
$$

2. Real-activity-related model (RA). As Shiu and Lam (2004); Chen et al. (2007); Narayan et al. (2008) note, there is a strong correlation between real economic growth and real activity variables such as electricity consumption. In such models, in addition to lagged industrial production, a variable correlated with the real economy, $X_{t}$, is included,

$$
y_{t}=\theta_{0}+\theta_{1} y_{t-h}+\theta_{2} X_{t-h}+\varepsilon_{t}, \varepsilon_{t} \sim N\left(0, \sigma_{t}^{2}\right) .
$$

We choose two alternatives for $X_{t}$, either the electricity consumption or a leading economic indicator constructed by National Bureau of Statistics of China, both retrieved from the CEIC database. We denote these two versions of RA models as RA1 and RA2.

3. Interest-rate term-structure model (TS). Based on the RA model, the nominal riskfree rate, represented by the one-month weighted average national interbank offered rate of the People's Bank of China, $r_{t}$, is included. This short-term interest rate is an important monetary policy instrument. It is closely linked to the business cycle and carries useful information for forecasting performance of the real economy in the short to medium run. While it would be useful to consider the term spread (the difference between long-term and short-term interest rates) as it may be more effective in predicting business cycles, we limit our term-structure information to the short rate. 
China has only had an active treasury bond market producing a meaningful yield curve since 2006. The TS model is thus written as

$$
y_{t}=\theta_{0}+\theta_{1} y_{t-h}+\theta_{2} X_{t-h}+\theta_{3} r_{t-h}+\varepsilon_{t}, \varepsilon_{t} \sim N\left(0, \sigma_{t}^{2}\right) .
$$

Here, the TS model with electricity consumption growth as additional related real activity $X_{t-h}$ is denoted as TS1, with the leading indicator as $X_{t-h}$ denoted as TS2, and with both variables in $X_{t-h}$ denoted as TS3.

4. Random walk (RW) model.

$$
\begin{gathered}
y_{t}=y_{t-h}+\varepsilon_{t}, \varepsilon_{t} \sim N\left(0, \sigma_{t}^{2}\right) . \\
\hat{y}_{t+h / t}=\hat{y}_{t} .
\end{gathered}
$$

5. Langrun survey forecast.

The CMRC Langrun survey forecast is a quarterly forecast at the annual frequency for year-on-year growth rate that dates from the third quarter of 2005. Our IP growth data, in contrast, are for monthly year-on-year growth rates. Thus we transform our monthly results for 3-, 6-, 9-, and 12-months ahead forecasts into quarterly year-onyear growth data corresponding to 1-, 2-, 3-, and 4-quarter ahead forecasts with the following equation (10) (Mariano and Murasawa, 2003):

$$
y_{t}=\frac{1}{3}\left(y_{t-2}^{*}+y_{t-1}^{*}+y_{t}^{*}\right),
$$

where $y_{t}$ denotes the transformed quarterly data, and $y_{t}^{*}$ represents the corresponding monthly data.

For the same underlying realization $y_{t}$, we compare the 1- to 4-quarter ahead LAR(1) forecasts $\left(\hat{y}_{t \mid t-h}, h=1, \ldots, 4\right)$ with (quasi) 1-quarter ahead Langrun forecasts $\left(\hat{y}_{t \mid t-1}\right)$.

\subsubsection{Alternative forecasts for the inflation rate}

1. Time-series model AR(1).

$$
\pi_{t}=\theta_{0}+\theta_{1} \pi_{t-h}+\varepsilon_{t}, \varepsilon_{t} \sim N\left(0, \sigma_{t}^{2}\right),
$$

and its corresponding forecast is

$$
\widehat{\pi}_{t+h / t}=\widehat{\theta}_{0}+\widehat{\theta}_{1} \pi_{t} .
$$


2. Phillips curve model (PC).

In addition to the lagged inflation, a variable proxying real activity, $X_{t}$, is also included:

$$
\pi_{t}=\theta_{0}+\theta_{1} \pi_{t-h}+\theta_{2} X_{t-h}+\varepsilon_{t}, \varepsilon_{t} \sim N\left(0, \sigma_{t}^{2}\right),
$$

where we choose two alternatives for $X_{t}$, either the IP growth or the leading economic indicator constructed by the National Bureau of Statistics of China. We denote these two versions as $\mathrm{PC} 1$ and $\mathrm{PC} 2$, respectively.

3. Interest-rate term-structure model (TS).

Based on the PC model, the nominal risk-free rate, represented by the one-month Chibor, $r_{t-h}$, is included to provide potential information closely linked to the business cycle.

$$
\pi_{t}=\theta_{0}+\theta_{1} \pi_{t-h}+\theta_{2} X_{t-h}+\theta_{3} r_{t-h}+\varepsilon_{t}, \varepsilon_{t} \sim N\left(0, \sigma_{t}^{2}\right) .
$$

The TS model with IP growth as $X_{t-h}$ is here denoted as TS1, with the leading indicator as $X_{t-h}$ denoted as TS2, and with both IP growth and the leading indicator as $X_{t-h}$ denoted as TS3.

4. Random walk model (RW).

$$
\begin{gathered}
\pi_{t}=\pi_{t-h}+\varepsilon_{t}, \varepsilon_{t} \sim N\left(0, \sigma_{t}^{2}\right) . \\
\hat{\pi}_{t+h / t}=\hat{\pi}_{t} .
\end{gathered}
$$

5. Langrun survey forecast.

As with the IP growth forecast, the CMRC Langrun survey forecast for inflation is also a quarterly forecast for year-on-year inflation from the third quarter of 2005 onwards, while our CPI inflation is a monthly year-on-year inflation rate. We thus transform our monthly forecasting results for 3-, 6-, 9-, and 12-month horizons into quarterly year-on-year growth data corresponding to 1-, 2-, 3-, and 4-quarter horizons with the following equation (17)(Mariano and Murasawa, 2003):

$$
\pi_{t}=\frac{1}{3}\left(\pi_{t-2}^{*}+\pi_{t-1}^{*}+\pi_{t}^{*}\right)
$$

where $\pi_{t}$ denotes the transformed quarterly inflation data, and $\pi_{t}^{*}$ represents the corresponding monthly inflation data.

For the same underlying realization $\pi_{t}$, we compare the 1- to 4-quarter horizon LAR(1) forecasts $\left(\hat{\pi}_{t \mid t-h}, h=1, \ldots, 4\right)$ with (quasi) 1-quarter horizon Langrun forecasts $\left(\hat{\pi}_{t \mid t-1}\right)$. 


\subsubsection{Alternative models for key interest rate}

1. Time-series model AR(1).

$$
r_{t}=\theta_{0}+\theta_{1} r_{t-h}+\varepsilon_{t}, \varepsilon_{t} \sim N\left(0, \sigma_{t}^{2}\right)
$$

and its corresponding forecast is

$$
\widehat{r}_{t+h / t}=\widehat{\theta}_{0}+\widehat{\theta}_{1} r_{t}
$$

2. Random walk (RW) model.

$$
\begin{gathered}
r_{t}=r_{t-h}+\varepsilon_{t}, \varepsilon_{t} \sim N\left(0, \sigma_{t}^{2}\right) . \\
\hat{r}_{t+h / t}=\hat{r}_{t} .
\end{gathered}
$$

\subsection{Measures of forecast comparison}

We use three measures as indicators of forecast precision, the forecast root mean squared error (RMSE), the mean absolute error (MAE) and the mean error (ME). We also compute the standard deviation of absolute errors $(\operatorname{Std}(\mathrm{AE}))$ and standard deviation of errors $(\operatorname{Std}(\mathrm{Err}))$ to evaluate the forecast variation.

- Root mean squared error, RMSE.

$$
R M S E=\sqrt{\frac{1}{T_{i}} \sum_{t=1}^{T_{i}}\left(x_{t}-\widehat{x}_{t}\right)^{2} .}
$$

- Mean absolute error, MAE, and standard deviation of absolute errors, Std(AE).

$$
\begin{aligned}
M A E & =\frac{1}{T_{i}} \sum_{t=1}^{T_{i}}\left|x_{t}-\widehat{x}_{t}\right|, \\
\operatorname{Std}(A E) & =\operatorname{std}\left(\left|x_{t}-\widehat{x}_{t}\right|\right),
\end{aligned}
$$

where $T_{i}$ is the forecasting interval, $\widehat{x}_{t}$ is the estimator for time $t$.

- Mean error, ME, and standard deviation of errors, Std(Err).

$$
\begin{aligned}
M E & =\frac{1}{T_{i}} \sum_{t=1}^{T_{i}}\left(x_{t}-\widehat{x}_{t}\right), \\
\operatorname{Std}(E r r) & =\operatorname{std}\left(x_{t}-\widehat{x}_{t}\right) .
\end{aligned}
$$




\section{Forecast results}

This section discusses comparison of forecasts, the potential monitoring function of the LAR approach on identifying shifts occurring as part of the economic transition, as well as robustness with respect to the forecast period.

\subsection{LAR model performance compared to alternative forecasts}

Table 4 reports the forecast RMSE and MAE, while Table 5 reports $\operatorname{Std}(\mathrm{AE})$ and $\operatorname{Std}(\mathrm{Err})$ for the macroeconomic variables with the selected forecast horizons.

For IP growth and the inflation rate, we compare the out-of-sample forecast performance for the LAR(1) model and the following alternative models and sample selection strategies:

(1) The autoregressive time-series model with three window-length strategies: 60- and 120-month rolling windows of fixed sample lengths, as well as a recursive window with expanding sample length.

(2) Other models with additional macroeconomic variables, including the real activity model (RA1, RA2) for IP growth and Phillips curve model (PC1, PC2) for inflation rate (both incorporating electricity or a leading indicator), and models incorporating the interest rate term structure (TS1, TS2, TS3) for IP growth and inflation. These models all have two alternative sample length strategies: a 60 -month rolling window with fixed length and a recursive window with expanding sample length.

(3) The random walk model.

For the weekly interest rate Chibor, we presents the results of $\operatorname{LAR}(1), \operatorname{AR}(1)$ with 130-week (2.5 year) and 260-week (5-year) rolling windows and a recursive window with expanding length, and the random walk.

In each column, the best forecast is indicated in bold across the forecast measure/horizon. The second-best forecast is underlined.

[Table 4. Forecast comparison of the three macroeconomic variables: RMSE and MAE]

[Table 5. Forecast comparison of the three macroeconomic variables: $\operatorname{Std}(\mathrm{AE})$ and

$$
\operatorname{Std}(\operatorname{Err})]
$$

Table 4 demonstrates that the LAR(1) model for the three macroeconomic variables always outperforms alternative models in 3- to 12-month ahead forecasts. Moreover, the advantage increases with the length of the forecast horizon. With respect to IP growth and inflation, the RMSE and the MAE for 6- to 12-month ahead forecasts with the LAR model achieve a nearly 40-50\% reduction compared to the second-best forecast. The superior 
performance of the LAR model over the alternatives is similar for the interest-rate forecast measured by RMSE and MAE, where both are the smallest for LAR in each forecast horizon.

Table 5 shows the LAR model outperforming the alternatives in 3- to 12-month ahead forecasts when forecast variance is considered in terms of standard deviation of mean absolute error and mean error. For IP growth, the reduction of standard errors tends to range between $10-40 \%$ as the forecast horizon increases from 3 months to 12 months. A similar pattern is found for the inflation-rate forecast.

Overall, the LAR model outperforms alternative models except at the very short end (1-week and 1-month ahead forecasts). The superior performance of 3- to 12-month ahead forecasts for IP growth and inflation rate, as well as 4- to 24-week ahead forecasts for the interest rate, are robust with respect to measures of RMSE, MAE and standard deviations of forecast errors.

In Figure 3, we plot forecast comparison between the LAR and TS2 recursive forecast for IP growth, TS3 rolling $60 \mathrm{~m}$ forecast for inflation rate, and AR $60 \mathrm{~m}$ rolling forecast for interest rate. The first two rows present the forecast of IP growth and inflation rate for 1-, 6-, 9- and 12-month ahead forecasts, and the last row for 1-, 4-, 12- and 24-week ahead interest-rate forecasts. The realized data are displayed with solid lines, LAR forecasts are displayed with dashed lines, while the alternative forecasts have dot-dashed lines.

Because they are so close, it can be difficult to distinguish between the three series for the 1-period ahead forecast. Nevertheless, as the forecast horizon increases, it is clear that the dashed line of the LAR forecast tracks the dynamics of actual data more closely than the alternatives. In particular, the LAR 6-month, 9-month and 12-month ahead forecasts promptly capture sharp falls in IP growth and the inflation rate for the large swings during the financial crisis in the period 2007-2010.

[Figure 3. Plots of the realized data with forecasts of LAR and representative comparing models]

In Table 6, we report the $R^{2}$ in the Mincer-Zarnowitz regressions (Mincer and Zarnowitz, 1969) and the Diebold-Mariano test statistics (Diebold and Mariano, 1995) to compare the LAR versus alternative model forecasts. In the Mincer-Zarnowitz (MZ) regression, we regress the observed actual data on the corresponding forecasts of model $i$ :

$$
y_{t}=\alpha+\beta \hat{y}_{t, i}+\varepsilon_{t}
$$

and take the determination coefficient $R^{2}$ as an indicator of forecast fit. Bold numbers indicate the highest $R^{2}$, the best forecast fit among the LAR and all alternatives. In the 
Diebold-Mariano (DM) test, we conduct a pairwise test on the equality of the mean squared forecast errors by regressing the difference between the squared forecast errors of the LAR model and the alternative model $i, e_{t, L A R}^{2}-e_{t, i}^{2}=\mu+\varepsilon_{t}$. The null hypothesis of equal performance is that $H_{0}: \mu=0$. We focus on the t-statistics of parameter $\mu$, denoted as DM t-stat, which favors the LAR if it is significantly negative (significance level marked by asterisks).

Table 6 shows that although the advantage of the LAR is insignificant for the 1-month ahead forecast for IP growth and inflation. However, it outperforms all alternative models in the 3- to 12-month ahead forecasts with the largest $R^{2}$ and significantly negative DM test statistics. Similar patterns hold for the interest-rate forecast across horizons.

[Table 6. Forecast comparison between the LAR and alternative models: MZ regression and DM test]

In Table 7, we compare the forecast performance of the LAR model against the CMRC Langrun survey: IP growth in panel a), and inflation rate in panel b). For comparison with the quarterly survey forecast, we transform our 3-, 6-, 9- and 12-month ahead forecast data into 1-, 2-, 3- and 4-quarter ahead year-on-year forecast data with equation (10) and (17). To match the same forecast period of inflation and IP growth, and in view of the incompleteness of the involved forecast institutes at the initial stage of CMRC survey, we discard the first two forecasts of the CMRC survey and conduct forecast comparison for both variables over the period 2006:Q1-2014:Q1. The CMRC column presents the 1-quarter ahead survey forecast. For the same targeted forecast period, we present 1- to 4-quarter ahead predictions of the LAR. We first report the measures of RMSE, MAE and standard deviations of errors. At the bottom of each panel, we provide two additional measures: the $R^{2}$ of $\mathrm{MZ}$ regression and the DM test statistics.

In panel a), the LAR outperforms the CMRC survey for IP growth on most measures, including smaller values for RMSE and standard deviation of errors and higher $R^{2}$ in the MZ regression in the case of the 1-quarter ahead prediction. Even in the 2-, 3- and 4-quarter ahead forecasts, the LAR model produces precision comparable to the 1-quarter horizon forecast and with higher $R^{2}$ in the MZ regressions and negative (even if not significant) DM t-statistics. In panel b), the performance of the LAR model matches that of the CMRC survey 1-quarter ahead inflation-rate forecast. The LAR model, however, produces overall satisfactory results compared to the survey forecast and delivers more timely prediction of forecast events than the CMRC survey.

[Table 7. Forecast Comparison between the LAR and CMRC survey] 
In Figure 4, we plot the LAR and CMRC survey forecasts for the IP growth rate and inflation rate 1-quarter ahead in the first row. The actual data are indicated with solid lines, LAR forecast with dashed lines and survey forecast with dot-dashed lines. The figure shows that the LAR and CMRC survey forecasts match the actual data both very well, but the LAR better forecasts the economic downturn in 2008. The second row presents the actual data with solid lines, together with the LAR forecasts 2-, 3- and 4-quarter ahead marked as dashed lines, dotted lines and dot-dashed lines, respectively. Even for the 2- to 4-quarter ahead predictions, the LAR model captures the realized data without showing the dramatic rising prediction errors that typically accompany longer horizon forecasts.

[Figure 4. Plots of the realized data with LAR and CMRC forecasts]

\subsection{Lengths of stable sub-samples}

Table 8 summarizes the average lengths for detected homogenous intervals of the three variables in each forecast horizon. The average sample length is relatively low with a mean value 19 months for IP growth. The average range of homogenous interval is $32-80$ months for inflation and 36-70 weeks for interest rates. These average stable lengths are much shorter than the traditionally used sample lengths of, say, 5 years, 10 years or even longer in rolling and recursive window forecasts.

[Table 8. Average lengths of homogeneous intervals detected by LAR]

Figure 5 presents the parameter evolution in the LAR model for a 1-period ahead forecast with the three variables. We see here that the estimated parameters change over time with abrupt breaks and gradual changes that indicate regime shifts. The financial crisis dramatically drags down the persistence of inflation and interest rate, and pushes up standard deviations for all variables to historical highs.

[Figure 5. Parameter evolution in the LAR model]

\subsection{Patterns of implied breaks and policy changes}

Having shown our LAR model predicts selected Chinese macroeconomic variables better than traditional alternatives, we now consider if there might be other benefits from the model's adaptive feature. Is useful information hidden in the detected breaks and parameter 
shifts that drives good predictive ability of the model? Understanding the time-varying features of state dynamics in real time, after all, could be valuable not just for forecasting, but for real-time diagnosis of the macroeconomy and policy making.

Figure 6 plots the detected stable sub-samples and breaks along the vertical time axis for each macroeconomic variable. We report the results of the 1-step ahead forecast of the LAR(1) model. The vertical axis denotes the time when the forecast is made. At each point of time, an optimal sub-sample is detected. This is shown as a light solid line along the horizontal time axis. At the end of the line, a dark dotted line indicates the period, in this case six months for IP growth and inflation rate and six weeks for interest rate, during which the most recent break happens such that the hypothesis of homogenous interval no longer holds. When these (dark blue) dotted lines are stacked along the forecast time, common areas of detected breaks become evident.

[Figure 6. Detected sub-samples of homogeneity]

Observing Figure 6, we find that the stable sub-samples of the inflation rate are relatively longer than those of IP growth and interest rate as illustrated by the average sample lengths in Table 8. The real variable, IP growth, has fewer clear cut breaks with short homogeneous intervals, suggesting gradual and smooth changes in the data-generating process. This finding echoes the gradual transition strategy of China and the diffusion of growth factors such as technology innovation, human capital development and the implementation of gradual institutional reforms. In contrast, the nominal variables for inflation rate and interest rate have several commonly identified ending periods of the homogeneous intervals, that is abrupt breaks in late 1994, early 2005 and early 2009 for inflation, and early 2004 and early 2008 for interest rates.

Nominal variables are prone to impacts of monetary policy and regime changes. Although break identification is purely data driven and a by-product of testing homogenous intervals for local estimation, commonly identified break periods in the nominal variables are quite in line with major policy changes. For instance, 1994 marks the official response to the economic overheating that began in 1992. At that time, the People's Bank of China (PBoC) embraced monetary policies that have ever since kept inflation below $10 \%$.

Over our common samples of interest rate and inflation between 2001 to 2014, the LAR identifies two break periods for each variable. The breaks for interest rate (early 2004 and early 2008) leads the breaks for inflation (early 2005 and early 2009) by about a year. This is consistent with the stickiness of price and sensitivity of interest rate to policy changes. However, what policy changes might have caused such substantial dynamic changes in the nominal variables? 
First, there was the launch of marketization of interest rates in China in January 1, 2004. The $\mathrm{PBoC}$ allowed commercial bank lending rates to float between 0.9 to 2 times the official lending rate. As a result, interest-rate formation became partly determined by the market and bank interest rates began to vary in response to supply and demand. There were also preparations for a change in exchange rate regime from a fixed to managed float in July 2005. A period of stable inflation ended as inflationary pressure began to build in mid-2005 in anticipation of yuan appreciation and large inflows of international capital.

Second, there was an abrupt change in monetary policy stance in the first half of 2008. At that time. the $\mathrm{PBoC}$ increased bank reserve requirements four times, eventually reaching 16.5\%, the highest level since 1985. The reserve ratio averaged about $10 \%$ between 1985 and 2007. This tightened monetary policy ended some of the overheating in credit markets and altered interest-rate dynamics. However, with global financial crisis depressing Chinese exports and economic growth, the drop in inflationary pressure turned into a deflation nightmare in 2009, and ending another period of stable inflation.

Overall, our LAR method is useful in monitoring structural breaks of the economic process, showing gradual and smooth transition in the real economic variable, and abrupt changes in nominal variables which are largely in line with major monetary policy shifts.

\subsection{Stability and robustness of the LAR forecast performance}

The LAR model demonstrates outstanding forecast performance for the three key macroeconomic variables. Is the performance restricted to the above-specified sample periods? The extreme large swings before 1997 may favor the LAR due to its quick detection and shedding off the initial period for the later forecast. Thus, the LAR may enjoy specific advantage in forecasting the IP growth and inflation rate compared to rolling window or recursive forecast of alternative models. To test the stability and robustness of the LAR forecast performance, we select the period of 1998:1 to 2007:12 as the initial sample to estimate and forecast the period of 2008:1 to 2014:3, a period that includes the global financial crisis. We use similar procedures to those described above, including the same set of alternative models and similar forecast comparison measures.

The results are summarized in Table 9. Panel a) reports the concrete estimation time spans and forecast intervals for each forecast horizon. Panels b) and c) provide the forecast comparison in terms of RMSE, MAE and standard deviations of errors. In each column, the first best is bolded and the second best underlined. Results in panel b) and c) yet again show that the LAR outperforms alternative models for 3- to 12-month ahead forecasts for both IP growth and inflation. The reduction in RMSE, MAE and standard deviations of errors remains in the range of $10-50 \%$ with respect to the second-best model. Again, the advantage increases with the forecast horizon. Panel d) provides the comparison with 
MZ regression and DM test, where the advantage of LAR begins to dominate alternative models starting from 3-month ahead forecast horizons with significant p-values, the highest R-square and significant negative DM statistics. This robustness check demonstrates that the advantage of the LAR in 3- to 12-month ahead forecasts of real activity and inflation is maintained across sample periods.

[Table 9. Robustness check with sub-sample forecast for IP growth and inflation rate]

\section{Conclusion}

This study demonstrates how a LAR model may be applied to forecasting three key macroeconomic variables for China in a way that captures the features of its transition economy. Our proposed method is shown to outperform popular models and window selection methods in predicting real and nominal out-of-sample variables, as well as display remarkable real-time monitoring power in detecting structural changes in the underlying economy. An ability to make timely, precise predictions can serve market participants and policymakers in assessing and monitoring economic dynamics.

Extension of the proposed LAR to forecasting other economic variables should be fairly straightforward. Future studies could also extend application of a LAR with exogenous variables (LARX) to improve forecasts and model-averaging based on an adaptive method. 


\section{References}

Ahumada HA, Garegnani ML. 2012. Forecasting a monetary aggregate under instability: Argentina after 2001. International Journal of Forecasting 28: 412-427.

Ang A, Bekaert G, Wei M. 2007. Do macro variables, asset markets, or surveys forecast inflation better? Journal of Monetary Economics 54: 1163-1212.

Bai J, Ng S. 2002. Determining the number of factors in approximate factor models. Econometrica 70: 191-221.

Bai J, Ng S. 2008. Forecasting economic time series using targeted predictors. Journal of Econometrics 146: 304-317.

Banerjee A, Marcellino M, Masten I. 2008. Forecasting macroeconomic variables using diffusion indexes in short samples with structural change, volume 3. Emerald Group Publishing Limited.

Belmonte M, Koop G. 2014. Model Switching and Model Averaging in Time-Varying Parameter Regression Models. Bayesian Model Comparison 34: 45-69.

Bräuning F, Koopman SJ. 2013. Forecasting macroeconomic variables using collapsed dynamic factor analysis. International Journal of Forecasting.

Castle JL, Clements MP, Hendry DF. 2013. Forecasting by factors, by variables, by both or neither? Journal of Econometrics 177: 305-319.

Chen ST, Kuo HI, Chen CC. 2007. The relationship between GDP and electricity consumption in 10 Asian countries. Energy Policy 35: 2611-2621.

Chen Y, Härdle WK, Pigorsch U. 2010. Localized realized volatility modeling. Journal of the American Statistical Association 105: 1376-1393.

Chen Y, Niu L. 2014. Adaptive dynamic Nelson-Siegel term structure model with applications. Journal of Econometrics 180: 98-115.

Chow GC. 2015. China's Economic Transformation. Wiley-Blackwell, third edition.

Clark TE, McCracken MW. 2010. Averaging forecasts from VARs with uncertain instabilities. Journal of Applied Econometrics 25: 5-29.

Clements MP, Hendry DF. 1996. Intercept Corrections and Structural Change. Journal of Applied Econometrics 11: 475-494. 
Clements MP, Hendry DF. 2008. Economic forecasting in a changing world. Capitalism and Society 3.

D'Agostino A, Gambetti L, Giannone D. 2013. Macroeconomic forecasting and structural change. Journal of Applied Econometrics 28: 82-101.

De Gooijer JG, Hyndman RJ. 2006. 25 years of time series forecasting. International Journal of Forecasting 22: 443-473.

Diebold FX, Mariano RS. 1995. Comparing predictive accuracy. Journal of Business and Economic Statistics 20: 253-263.

Forni M, Hallin M, Lippi M, Reichlin L. 2000. The generalized dynamic-factor model: identification and estimation. Review of Economics and Statistics 82: 540-554.

Forni M, Hallin M, Lippi M, Reichlin L. 2003. Do financial variables help forecasting inflation and real activity in the EURO area? Journal of Monetary Economics 50: 1243-1255.

Geweke J, Jiang Y. 2011. Inference and prediction in a multiple-structural-break model. Journal of Econometrics 163: 172-185.

Härdle WK, Hautsch N, Mihoci A. 2014a. Local adaptive multiplicative error models for high-frequency forecasts. Journal of Applied Econometrics .

Härdle WK, Mihoci A, Ting CHA. 2014b. Adaptive order flow forecasting with multiplicative error models. Technical report, Sonderforschungsbereich 649, Humboldt University, Berlin, Germany.

Krkoska L, Teksoz U. 2007. Accuracy of GDP growth forecasts for transition countries: Ten years of forecasting assessed. International Journal of Forecasting 23: 29-45.

Lin JY. 2013. Demystifying the Chinese Economy. Australian Economic Review 46: 259268.

Mariano RS, Murasawa Y. 2003. A new coincident index of business cycles based on monthly and quarterly series. Journal of Applied Econometrics 18: 427-443.

Mincer JA, Zarnowitz V. 1969. The evaluation of economic forecasts. In Economic Forecasts and Expectations: Analysis of Forecasting Behavior and Performance. NBER, 1-46.

Narayan PK, Narayan S, Prasad A. 2008. A structural VAR analysis of electricity consumption and real GDP: evidence from the G7 countries. Energy Policy 36: 2765-2769.

Naughton B. 2007. The Chinese economy: transitions and growth. MIT press. 
Rossi B, Sekhposyan T. 2010. Have economic models' forecasting performance for US output growth and inflation changed over time, and when? International Journal of Forecasting 26: $808-835$.

Shiu A, Lam PL. 2004. Electricity consumption and economic growth in China. Energy policy 32: 47-54.

Stock J, Watson M. 2009. Forecasting in dynamic factor models subject to structural instability. The Methodology and Practice of Econometrics. A Festschrift in Honour of David F. Hendry : 173-205.

Stock JH, Watson MW. 1999. Forecasting inflation. Journal of Monetary Economics 44: 293-335.

Stock JH, Watson MW. 2002a. Forecasting using principal components from a large number of predictors. Journal of the American Statistical Association 97: 1167-1179.

Stock JH, Watson MW. 2002b. Macroeconomic forecasting using diffusion indexes. Journal of Business and Economic Statistics 20: 147-162.

Stock JH, Watson MW. 2007. Why has US inflation become harder to forecast? Journal of Money, Credit and Banking 39: 3-33.

Stock JH, Watson MW. 2008. Phillips curve inflation forecasts. Technical report, National Bureau of Economic Research. 
Table 1. Statistics of the three macroeconomic variables

\begin{tabular}{cccccc}
\hline Variables & $\begin{array}{l}\text { Sample } \\
\text { periods }\end{array}$ & Mean(\%) & Std(\%) & Skewness & Kurtosis \\
\hline Growth of industrial production & 231 & 12.918 & 3.691 & -0.036 & 2.756 \\
Inflation rate & 267 & 4.690 & 6.409 & 1.813 & 5.888 \\
Interest rate & 682 & 2.669 & 1.166 & 1.971 & 9.301 \\
\hline
\end{tabular}

\section{Notes:}

The first row is monthly data of the growth rate of industrial production from 1995:1 to 2014:3; the second row is the monthly CPI inflation rate from 1992:1 to 2014:3; the third row is the selected interest rate, the weekly 7-day Chibor (China Interbank Offered Rate), taken from the weighted average closing rate of the last trading day of a week, from January 2001 to March 2014. All data are from CEIC China Economic and Industry Database. 
Table 2. Initial samples of estimation and periods of forecast comparison

a) IP growth

\begin{tabular}{|c|c|c|c|c|}
\hline & \multicolumn{2}{|c|}{ The maximal interval of the initial sample } & \multicolumn{2}{|c|}{ Out-of-sample forecast comparison } \\
\hline $\begin{array}{c}\text { Forecast } \\
\text { horizon } h \\
\text { (month) }\end{array}$ & $\begin{array}{l}\text { Dependent variable } \\
\text { interval }\end{array}$ & $\begin{array}{l}\text { Explanatory variable } \\
\text { in lag term }\end{array}$ & Forecast interval & $\begin{array}{l}\text { Number of forecast } \\
\text { periods }\end{array}$ \\
\hline 1 & 1995:02-2003:12 & 1995:01-2001:11 & 2005:01-2014:03 & 111 \\
\hline 3 & 1995:04-2005:02 & $1995: 01-2001: 11$ & 2005:03-2014:03 & 109 \\
\hline 6 & 1995:07-2005:05 & 1995:01-2001:11 & 2005:06-2014:03 & 106 \\
\hline 9 & $1995: 10-2005: 08$ & 1995:01-2001:11 & 2005:09-2014:03 & 103 \\
\hline 12 & 1996:01-2005:11 & 1995:01-2001:11 & 2005:12-2014:03 & 100 \\
\hline \multicolumn{5}{|c|}{ b) Inflation rate } \\
\hline & \multicolumn{2}{|c|}{ The maximal interval of the initial sample } & \multicolumn{2}{|c|}{ Out-of-sample forecast comparison } \\
\hline $\begin{array}{c}\text { Forecast } \\
\text { horizon } h \\
\text { (month) }\end{array}$ & $\begin{array}{l}\text { Dependent variable } \\
\text { interval }\end{array}$ & $\begin{array}{l}\text { Explanatory variable } \\
\text { in lag term }\end{array}$ & Forecast interval & $\begin{array}{l}\text { Number of forecast } \\
\text { periods }\end{array}$ \\
\hline 1 & 1992:02-2001:12 & 1992:01-2001:11 & 2002:01-2014:03 & 147 \\
\hline 3 & 1992:04-2002:02 & 1992:01-2001:11 & 2002:03-2014:03 & 145 \\
\hline 6 & 1992:07-2002:05 & 1992:01-2001:11 & 2002:06-2014:03 & 142 \\
\hline 9 & $1992: 10-2002: 08$ & 1992:01-2001:11 & 2002:09-2014:03 & 139 \\
\hline 12 & 1993:01-2002:11 & 1992:01-2001:11 & 2002:12-2014:03 & 136 \\
\hline \multicolumn{5}{|c|}{ c) Interest rate } \\
\hline & \multicolumn{2}{|c|}{ The maximal interval of the initial sample } & \multicolumn{2}{|c|}{ Out-of-sample forecast comparison } \\
\hline $\begin{array}{c}\text { Forecast } \\
\text { horizon } h \\
\text { (week) }\end{array}$ & $\begin{array}{l}\text { Dependent variable } \\
\text { interval }\end{array}$ & $\begin{array}{l}\text { Explanatory variable } \\
\text { in lag term }\end{array}$ & Forecast interval & $\begin{array}{c}\text { Number of forecast } \\
\text { periods }\end{array}$ \\
\hline 1 & 2001:02-2005:52 & 2001:01-2005:51 & 2006:01-2014:14 & 426 \\
\hline 4 & 2001:05-2006:03 & $2001: 01-2005: 51$ & 2006:04-2014:14 & 423 \\
\hline 12 & $2001: 14-2006: 12$ & 2001:01-2005:51 & 2006:13-2014:14 & 414 \\
\hline 24 & $2001: 28-2006: 26$ & 2001:01-2005:51 & $2006: 27-2014: 14$ & 401 \\
\hline
\end{tabular}


Table 3. Summary of involved data in alternative models

\begin{tabular}{ccc}
\hline Variables & Frequency & Sample data interval \\
\hline $\begin{array}{c}\text { Growth of industrial production } \\
\text { Growth of electricity consumption }\end{array}$ & monthly & 1995:M1-2014:M3 \\
Leading economic indicator & monthly & 1996:M2-2014:M3 \\
$\begin{array}{c}\text { 1nflation rate } \\
\text { One-month weighted average Chibor rate }\end{array}$ & monthly & 1996:M1-2014:M3 \\
average) & monthly & 1992:M1-2014:M3 \\
7-day Chibor rate(weekly weighted & weekly & 2001:M1-2014:M3 \\
CMRC Langrun survey data & & 2006:Q1-2014:Q1 \\
\hline
\end{tabular}


Table 4. Forecast comparison of the three macroeconomic variables: RMSE and MAE

a) IP growth

\begin{tabular}{|c|c|c|c|c|c|c|c|c|c|c|}
\hline & \multicolumn{2}{|c|}{$\mathrm{h}=1 \mathrm{~m}$} & \multicolumn{2}{|c|}{$h=3 m$} & \multicolumn{2}{|c|}{$h=6 m$} & \multicolumn{2}{|c|}{$\mathrm{h}=9 \mathrm{~m}$} & \multicolumn{2}{|c|}{$h=12 m$} \\
\hline & RMSE & MAE & RMSE & MAE & RMSE & MAE & RMSE & MAE & RMSE & MAE \\
\hline $\operatorname{LAR}(1)$ & 1.195 & 0.875 & 1.640 & 1.262 & 1.695 & 1.254 & 1.725 & 1.206 & 1.591 & 1.104 \\
\hline AR Rolling $60 \mathrm{~m}$ & 1.165 & 0.842 & 2.130 & 1.474 & 3.023 & 2.228 & 3.386 & 2.565 & 3.460 & 2.618 \\
\hline AR Rolling $120 \mathrm{~m}$ & 1.117 & 0.832 & 2.083 & 1.503 & 3.149 & 2.474 & 3.757 & 3.024 & 4.076 & 3.280 \\
\hline AR Recursive & 1.107 & 0.814 & 2.033 & 1.437 & 2.993 & 2.199 & 3.497 & 2.631 & 3.727 & 2.839 \\
\hline RA1 Rolling 60m & 1.169 & 0.863 & 2.145 & 1.486 & 3.045 & 2.246 & 3.440 & 2.592 & 3.491 & 2.634 \\
\hline RA1 Recursive & 1.105 & 0.823 & 2.042 & 1.429 & 3.012 & 2.216 & 3.524 & 2.647 & 3.749 & 2.847 \\
\hline RA2 Rolling 60m & 1.071 & 0.786 & 1.946 & 1.350 & 2.904 & 2.114 & 3.359 & 2.569 & 3.409 & 2.697 \\
\hline RA2 Recursive & 1.029 & 0.778 & 1.907 & 1.344 & 2.896 & 2.145 & 3.529 & 2.690 & 3.854 & 2.896 \\
\hline TS1 Rolling 60m & 1.157 & 0.856 & 2.060 & 1.407 & 2.789 & $\underline{1.989}$ & 2.947 & $\underline{2.184}$ & 2.821 & 2.313 \\
\hline TS1 Recursive & 1.096 & 0.811 & 1.990 & 1.361 & 2.854 & 2.073 & 3.247 & 2.477 & 3.341 & 2.616 \\
\hline TS2 Rolling 60m & 1.090 & 0.806 & 2.003 & 1.436 & 2.875 & 2.065 & 2.957 & 2.226 & $\underline{2.514}$ & $\underline{2.024}$ \\
\hline TS2 Recursive & 1.032 & 0.778 & 1.897 & 1.306 & 2.817 & 2.051 & 3.268 & 2.513 & 3.330 & 2.581 \\
\hline TS3 Rolling 60m & 1.093 & 0.828 & 2.030 & 1.453 & 2.910 & 2.107 & 3.011 & 2.274 & 2.540 & 2.031 \\
\hline TS3 Recursive & 1.030 & 0.778 & 1.902 & 1.298 & 2.822 & 2.058 & 3.275 & 2.514 & 3.332 & 2.582 \\
\hline Random Walk & 1.106 & 0.827 & 2.111 & 1.445 & 3.330 & 2.379 & 4.144 & 2.944 & 4.646 & 3.275 \\
\hline
\end{tabular}

b) Inflation rate

\begin{tabular}{|c|c|c|c|c|c|c|c|c|c|c|}
\hline & \multicolumn{2}{|c|}{$\mathrm{h}=1 \mathrm{~m}$} & \multicolumn{2}{|c|}{$\mathrm{h}=3 \mathrm{~m}$} & \multicolumn{2}{|c|}{$\mathrm{h}=6 \mathrm{~m}$} & \multicolumn{2}{|c|}{$\mathrm{h}=9 \mathrm{~m}$} & \multicolumn{2}{|c|}{$\mathrm{h}=12 \mathrm{~m}$} \\
\hline & RMSE & MAE & RMSE & MAE & RMSE & MAE & RMSE & MAE & RMSE & MAE \\
\hline $\operatorname{LAR}(1)$ & $\underline{0.583}$ & $\underline{0.448}$ & 0.888 & 0.754 & 0.967 & 0.772 & 1.024 & 0.791 & 1.075 & 0.807 \\
\hline AR Rolling $60 \mathrm{~m}$ & 0.675 & 0.515 & 1.281 & 0.994 & 1.922 & 1.491 & 2.234 & 1.711 & 2.267 & 1.753 \\
\hline AR Rolling 120m & 0.667 & 0.514 & 1.280 & 1.009 & 2.011 & 1.564 & 2.506 & 1.932 & 2.741 & 2.076 \\
\hline AR Recursive & 0.664 & 0.507 & 1.276 & 0.984 & 2.052 & 1.563 & 2.655 & 2.053 & 3.053 & 2.372 \\
\hline RA1 Rolling 60m & 0.599 & 0.466 & 1.178 & 0.963 & 1.838 & 1.444 & 2.169 & 1.674 & 2.110 & 1.544 \\
\hline RA1 Recursive & 0.587 & 0.442 & 1.127 & 0.912 & 1.819 & 1.454 & 2.321 & 1.864 & 2.639 & 2.122 \\
\hline RA2 Rolling 60m & 0.619 & 0.484 & 1.031 & 0.848 & 1.549 & 1.230 & $\underline{1.860}$ & $\underline{1.453}$ & $\underline{2.009}$ & $\underline{1.477}$ \\
\hline RA2 Recursive & 0.620 & 0.475 & 1.102 & 0.872 & 1.779 & 1.363 & 2.378 & 1.787 & 2.983 & 2.230 \\
\hline TS1 Rolling 60m & 0.597 & 0.459 & 1.168 & 0.958 & 1.865 & 1.479 & 2.232 & 1.748 & 2.208 & 1.700 \\
\hline TS1 Recursive & 0.592 & $\underline{0.448}$ & 1.143 & 0.922 & 1.832 & 1.461 & 2.279 & 1.809 & 2.444 & 1.941 \\
\hline TS2 Rolling 60m & 0.618 & 0.485 & $\underline{0.991}$ & 0.812 & 1.530 & 1.246 & 1.899 & 1.507 & 2.116 & 1.596 \\
\hline TS2 Recursive & 0.621 & 0.480 & 1.078 & 0.865 & 1.693 & 1.341 & 2.119 & 1.650 & 2.409 & 1.857 \\
\hline TS3 Rolling 60m & 0.582 & 0.451 & 0.992 & $\underline{0.809}$ & 1.550 & 1.251 & 1.921 & 1.512 & 2.116 & 1.617 \\
\hline TS3 Recursive & 0.590 & 0.451 & 1.061 & 0.859 & 1.684 & 1.350 & 2.113 & 1.668 & 2.372 & 1.869 \\
\hline Random Walk & 0.663 & 0.505 & 1.292 & 0.999 & 2.143 & 1.657 & 2.905 & 2.271 & 3.549 & 2.820 \\
\hline
\end{tabular}

c) Interest rate

\begin{tabular}{|c|c|c|c|c|c|c|c|c|}
\hline & \multicolumn{2}{|c|}{$h=1 w$} & \multicolumn{2}{|c|}{$h=4 w$} & \multicolumn{2}{|c|}{$h=12 w$} & \multicolumn{2}{|c|}{$h=24 w$} \\
\hline & RMSE & MAE & RMSE & MAE & RMSE & MAE & RMSE & MAE \\
\hline $\operatorname{LAR}(1)$ & 0.922 & 0.527 & 1.074 & 0.628 & 1.063 & 0.652 & 1.110 & 0.695 \\
\hline AR Rolling 30m & 0.979 & 0.603 & 1.104 & 0.712 & $\underline{1.212}$ & $\underline{0.770}$ & 1.286 & 0.868 \\
\hline AR Rolling 60m & $\underline{0.951}$ & 0.590 & $\underline{1.097}$ & $\underline{0.705}$ & 1.231 & 0.780 & 1.231 & $\underline{0.816}$ \\
\hline AR Recursive & 0.962 & 0.596 & 1.113 & 0.719 & 1.271 & 0.818 & 1.285 & 0.867 \\
\hline Random Walk & 1.006 & 0.546 & 1.191 & 0.737 & 1.441 & 0.895 & 1.416 & 0.990 \\
\hline
\end{tabular}

\section{Notes:}

$h$ denotes the forecast horizon. Std(AE) denotes the standard deviation of the absolute forecast errors, and Std(Err) denotes the standard deviation of the forecast errors. For each column, the best forecast, i.e., the smallest Std(AE) or Std(Err), is marked in bold-face; the second best is underlined. When the first and second best are the same, both are marked in bold-face, and no second best is further indicated. When the second and third best are the same, both are underlined. 
Table 5. Forecast comparison of the three macroeconomic variables: $\operatorname{Std}(\mathrm{AE})$ and $\operatorname{Std}(\mathrm{Err})$

a) IP growth

\begin{tabular}{|c|c|c|c|c|c|c|c|c|c|c|}
\hline & \multicolumn{2}{|c|}{$\mathrm{h}=1 \mathrm{~m}$} & \multicolumn{2}{|c|}{$h=3 m$} & \multicolumn{2}{|c|}{$\mathrm{h}=6 \mathrm{~m}$} & \multicolumn{2}{|c|}{$\mathrm{h}=9 \mathrm{~m}$} & \multicolumn{2}{|c|}{$h=12 m$} \\
\hline & $\operatorname{Std}(A E)$ & Std(Err) & $\operatorname{Std}(A E)$ & Std(Err) & $\operatorname{Std}(A E)$ & Std(Err) & $\operatorname{Std}(A E)$ & Std(Err) & $\operatorname{Std}(A E)$ & Std(Err) \\
\hline $\operatorname{LAR}(1)$ & 0.812 & 1.195 & 1.037 & 1.640 & 1.139 & 1.695 & 1.234 & 1.725 & 1.146 & 1.591 \\
\hline AR Rolling 60m & 0.810 & 1.164 & 1.537 & 2.111 & 2.044 & 2.910 & 2.211 & 3.075 & 2.263 & 2.870 \\
\hline AR Rolling $120 \mathrm{~m}$ & 0.748 & 1.114 & 1.442 & 2.058 & 1.986 & 3.052 & 2.230 & 3.555 & 2.420 & 3.769 \\
\hline AR Recursive & 0.750 & 1.107 & 1.439 & 2.032 & 2.043 & 2.986 & 2.340 & 3.471 & 2.414 & 3.679 \\
\hline RA1 Rolling 60m & 0.793 & 1.168 & 1.547 & 2.127 & 2.056 & 2.927 & 2.261 & 3.119 & 2.292 & 2.882 \\
\hline RA1 Recursive & 0.738 & 1.105 & 1.458 & 2.039 & 2.058 & 2.998 & 2.371 & 3.491 & 2.439 & 3.691 \\
\hline RA2 Rolling 60m & 0.740 & 1.050 & 1.426 & 1.867 & 1.991 & 2.660 & 2.165 & 3.048 & 2.085 & 3.047 \\
\hline RA2 Recursive & 0.676 & 1.025 & 1.354 & 1.896 & 1.960 & 2.865 & 2.323 & 3.473 & 2.542 & 3.774 \\
\hline TS1 Rolling 60m & 0.778 & 1.157 & 1.505 & 2.053 & 1.956 & 2.699 & 1.979 & $\underline{2.683}$ & 1.616 & 2.388 \\
\hline TS1 Recursive & 0.739 & 1.094 & 1.451 & 1.976 & 1.962 & 2.802 & 2.132 & 3.132 & 2.078 & 3.125 \\
\hline TS2 Rolling 60m & 0.733 & 1.038 & 1.397 & 1.866 & 2.001 & 2.571 & 1.947 & 2.698 & 1.491 & $\underline{2.337}$ \\
\hline TS2 Recursive & 0.681 & 1.028 & 1.376 & 1.873 & 1.931 & 2.746 & 2.123 & 3.148 & 2.104 & 3.131 \\
\hline TS3 Rolling 60m & 0.714 & 1.046 & 1.418 & 1.887 & 2.008 & 2.595 & 1.973 & 2.745 & 1.525 & 2.366 \\
\hline TS3 Recursive & $\underline{0.677}$ & 1.026 & 1.390 & 1.878 & 1.931 & 2.751 & 2.132 & 3.155 & 2.106 & 3.132 \\
\hline Random Walk & 0.737 & 1.105 & 1.544 & 2.105 & 2.329 & 3.313 & 2.917 & 4.111 & 3.296 & 4.584 \\
\hline \multicolumn{11}{|c|}{ b) Inflation rate } \\
\hline & \multicolumn{2}{|c|}{$h=1 m$} & \multicolumn{2}{|c|}{$\mathrm{h}=3 \mathrm{~m}$} & \multicolumn{2}{|c|}{$\mathrm{h}=6 \mathrm{~m}$} & \multicolumn{2}{|c|}{$h=9 m$} & \multicolumn{2}{|c|}{$h=12 m$} \\
\hline & $\operatorname{Std}(A E)$ & $\operatorname{Std}(E \operatorname{rr})$ & $\operatorname{Std}(A E)$ & $\operatorname{Std}(\operatorname{Err})$ & $\operatorname{Std}(A E)$ & $\operatorname{Std}(E r r)$ & $\operatorname{Std}(A E)$ & $\operatorname{Std}(\mathrm{Err})$ & $\operatorname{Std}(A E)$ & $\operatorname{Std}(E \operatorname{rr})$ \\
\hline $\operatorname{LAR}(1)$ & $\underline{0.374}$ & 0.683 & $\underline{0.574}$ & 0.988 & 0.714 & 1.067 & 0.730 & 1.094 & 0.710 & 1.075 \\
\hline AR Rolling 60m & 0.438 & 0.675 & 0.813 & 1.278 & 1.220 & 1.916 & 1.436 & 2.213 & 1.444 & 2.178 \\
\hline AR Rolling $120 \mathrm{~m}$ & 0.427 & 0.665 & 0.807 & 1.270 & 1.278 & 1.981 & 1.596 & 2.437 & 1.789 & 2.593 \\
\hline AR Recursive & 0.429 & 0.663 & 0.815 & 1.275 & 1.330 & 2.052 & 1.692 & 2.653 & 1.923 & 3.046 \\
\hline RA1 Rolling 60m & 0.377 & 0.595 & 0.680 & 1.146 & 1.138 & 1.790 & 1.410 & 2.117 & 1.438 & 1.990 \\
\hline RA1 Recursive & 0.386 & $\underline{0.586}$ & 0.662 & 1.100 & 1.092 & 1.729 & 1.390 & 2.202 & 1.569 & 2.491 \\
\hline RA2 Rolling 60m & 0.392 & 0.617 & 0.586 & 1.020 & 0.944 & 1.531 & 1.161 & 1.844 & 1.362 & 1.954 \\
\hline RA2 Recursive & 0.403 & 0.619 & 0.681 & 1.100 & 1.155 & 1.778 & 1.572 & 2.378 & 1.986 & 2.975 \\
\hline TS1 Rolling 60m & 0.383 & 0.595 & 0.669 & 1.153 & 1.142 & 1.852 & 1.394 & 2.216 & 1.437 & 2.155 \\
\hline TS1 Recursive & 0.387 & 0.591 & 0.679 & 1.134 & 1.108 & 1.810 & 1.426 & 2.231 & 1.509 & 2.332 \\
\hline TS2 Rolling 60m & 0.383 & 0.618 & 0.573 & $\underline{0.990}$ & $\underline{0.888}$ & 1.530 & 1.158 & 1.897 & 1.398 & 2.097 \\
\hline TS2 Recursive & 0.399 & 0.620 & 0.650 & 1.068 & 1.037 & 1.671 & 1.346 & 2.076 & 1.573 & 2.319 \\
\hline TS3 Rolling 60m & 0.368 & 0.581 & 0.581 & 0.991 & 0.915 & 1.550 & 1.185 & 1.921 & 1.381 & 2.098 \\
\hline TS3 Recursive & 0.380 & 0.589 & 0.623 & 1.050 & 1.006 & 1.660 & 1.314 & 2.070 & 1.491 & 2.276 \\
\hline Random Walk & 0.429 & 0.662 & 0.826 & 1.290 & 1.392 & 2.138 & 1.837 & 2.896 & 2.181 & 3.536 \\
\hline
\end{tabular}

c) Interest rate

\begin{tabular}{|c|c|c|c|c|c|c|c|c|}
\hline & \multicolumn{2}{|c|}{$h=1 w$} & \multicolumn{2}{|c|}{$\mathrm{h}=4 \mathrm{w}$} & \multicolumn{2}{|c|}{$h=12 w$} & \multicolumn{2}{|c|}{$\mathrm{h}=24 \mathrm{w}$} \\
\hline & $\operatorname{Std}(A E)$ & $\operatorname{Std}(\operatorname{Err})$ & $\operatorname{Std}(A E)$ & $\operatorname{Std}(\operatorname{Err})$ & $\operatorname{Std}(A E)$ & $\operatorname{Std}(E r r)$ & $\operatorname{Std}(A E)$ & $\operatorname{Std}(\mathrm{Err})$ \\
\hline $\operatorname{LAR}(1)$ & 0.754 & 0.922 & 0.871 & 1.074 & 0.839 & 1.063 & 0.865 & 1.110 \\
\hline AR Rolling $30 \mathrm{~m}$ & 0.773 & 0.978 & $\underline{0.851}$ & 1.100 & $\underline{0.947}$ & 1.194 & 0.951 & 1.279 \\
\hline AR Rolling $60 \mathrm{~m}$ & $\underline{0.755}$ & $\underline{0.941}$ & 0.849 & 1.081 & 0.952 & 1.190 & $\underline{0.922}$ & 1.185 \\
\hline AR Recursive & 0.761 & 0.944 & 0.854 & 1.087 & 0.973 & 1.213 & 0.949 & 1.210 \\
\hline Random Walk & 0.845 & 1.006 & 0.936 & 1.191 & 1.131 & 1.439 & 1.024 & 1.406 \\
\hline
\end{tabular}

Notes:

$h$ denotes the forecast horizon. Std(AE) denotes the standard deviation of the absolute forecast errors, and Std(Err) denotes the standard deviation of the forecast errors. For each column, the best forecast, i.e., the smallest Std(AE) or Std(Err), is marked in bold-face; the second best is underlined. When the first and second best are the same, both are marked in bold-face, and no second best is further indicated. When the second and third best are the same, both are underlined. 
Table 6. Forecast comparison between the LAR and alternative models: MZ regression and DM test

a) IP growth

\begin{tabular}{|c|c|c|c|c|c|c|c|c|c|c|c|c|c|c|c|}
\hline & \multicolumn{3}{|c|}{$h=1 m$} & \multicolumn{3}{|c|}{$h=3 m$} & \multicolumn{3}{|c|}{$\mathrm{h}=6 \mathrm{~m}$} & \multicolumn{3}{|c|}{$h=9 m$} & \multicolumn{3}{|c|}{$h=12 m$} \\
\hline & p_v & $R^{2}$ & DM t-stat. & p_v & $R^{2}$ & DM t-stat. & p_v & $R^{2}$ & DM t-stat. & p_v & $R^{2}$ & DM t-stat. & p_v & $R^{2}$ & DM t-stat. \\
\hline$\underline{\operatorname{LAR}(1)}$ & 0.323 & 0.885 & & 0.301 & 0.811 & & 0.297 & 0.775 & & 0.432 & 0.765 & & 0.426 & 0.803 & \\
\hline AR Rolling 60m & 0.640 & 0.888 & 0.526 & 0.316 & 0.642 & -1.396 & 0.315 & 0.320 & $-2.125^{* *}$ & 0.099 & 0.245 & $-2.000^{* *}$ & 0.000 & 0.436 & $-2.359^{* *}$ \\
\hline AR Rolling $120 \mathrm{~m}$ & 0.812 & 0.897 & 1.267 & 0.499 & 0.652 & $-1.552^{*}$ & 0.179 & 0.262 & $-2.972^{* * *}$ & 0.160 & 0.051 & $-2.956^{* * *}$ & 0.151 & 0.000 & $-3.089^{* * *}$ \\
\hline AR Recursive & 0.949 & 0.898 & 1.371 & 0.828 & 0.661 & -1.333 & 0.423 & 0.301 & $-2.635^{* * *}$ & 0.405 & 0.109 & $-2.497^{* * *}$ & 0.471 & 0.032 & $-2.470^{* * *}$ \\
\hline RA1 Rolling 60m & 0.605 & 0.888 & 0.439 & 0.316 & 0.636 & -1.454 & 0.301 & 0.313 & $-2.148^{* *}$ & 0.107 & 0.220 & $-1.994^{* *}$ & 0.000 & 0.415 & $-2.380^{* *}$ \\
\hline RA1 Recursive & 0.982 & 0.898 & 1.369 & 0.630 & 0.660 & -1.366 & 0.301 & 0.304 & $-2.622^{* * *}$ & 0.357 & 0.107 & $-2.457^{* * *}$ & 0.431 & 0.034 & $-2.431^{* *}$ \\
\hline RA2 Rolling 60m & 0.073 & 0.911 & 1.470 & 0.056 & $\underline{0.730}$ & -1.040 & 0.067 & 0.441 & $-1.876^{*}$ & 0.113 & 0.254 & $-1.982^{* * *}$ & 0.180 & 0.265 & $-2.627^{* * *}$ \\
\hline RA2 Recursive & 0.565 & 0.913 & $2.320^{* *}$ & 0.388 & 0.709 & -1.139 & 0.194 & 0.368 & $-2.648^{* * *}$ & 0.243 & 0.130 & $-2.411^{* *}$ & 0.305 & 0.031 & $-2.336^{* *}$ \\
\hline TS1 Rolling 60m & 0.322 & 0.891 & 0.597 & 0.045 & 0.674 & -1.332 & 0.166 & 0.435 & $-1.852^{*}$ & 0.115 & $\underline{0.426}$ & $-1.656^{*}$ & 0.017 & 0.550 & $-3.115^{* * *}$ \\
\hline TS1 Recursive & 0.836 & 0.901 & 1.431 & 0.680 & 0.679 & -1.191 & 0.415 & 0.371 & $-2.339^{* *}$ & 0.434 & 0.223 & $-2.198^{* *}$ & 0.303 & 0.221 & $-2.390^{* *}$ \\
\hline TS2 Rolling 60m & 0.011 & 0.911 & 1.138 & 0.023 & 0.728 & -1.423 & 0.023 & $\underline{0.487}$ & $-1.951^{* *}$ & 0.132 & 0.417 & $-1.743^{*}$ & 0.142 & $\underline{0.564}$ & $-2.733^{* * *}$ \\
\hline TS2 Recursive & 0.449 & 0.913 & $2.299^{* *}$ & 0.283 & 0.717 & -1.041 & 0.250 & 0.404 & $-2.334^{* *}$ & 0.404 & 0.218 & $-2.227^{* *}$ & 0.365 & 0.218 & $-2.405^{* *}$ \\
\hline TS3 Rolling 60m & 0.017 & 0.910 & 1.116 & 0.020 & 0.722 & $-1.517^{*}$ & 0.020 & 0.479 & $-1.994^{* *}$ & 0.130 & 0.398 & $-1.769^{* *}$ & 0.138 & 0.554 & $-2.752^{* * *}$ \\
\hline TS3 Recursive & 0.466 & 0.913 & $2.277^{* *}$ & 0.291 & 0.715 & -1.060 & 0.249 & 0.403 & $-2.333^{* *}$ & 0.408 & 0.215 & $-2.202^{* *}$ & 0.362 & 0.218 & $-2.395^{* *}$ \\
\hline Random Walk & 0.351 & 0.900 & 1.517 & 0.016 & 0.663 & $-1.548^{*}$ & 0.004 & 0.294 & $-2.724^{* * *}$ & 0.014 & 0.088 & $-2.343^{* *}$ & 0.022 & 0.013 & $-2.181^{* *}$ \\
\hline
\end{tabular}


b) Inflation rate

\begin{tabular}{|c|c|c|c|c|c|c|c|c|c|c|c|c|c|c|c|}
\hline & \multicolumn{3}{|c|}{$h=1 m$} & \multicolumn{3}{|c|}{$\mathrm{h}=3 \mathrm{~m}$} & \multicolumn{3}{|c|}{$\mathrm{h}=6 \mathrm{~m}$} & \multicolumn{3}{|c|}{$\mathrm{h}=9 \mathrm{~m}$} & \multicolumn{3}{|c|}{$h=12 m$} \\
\hline & p_v & $R^{2}$ & DM t-stat. & p_v & $R^{2}$ & DM t-stat. & p_v & $R^{2}$ & DM t-stat. & p_v & $R^{2}$ & DM t-stat. & p_v & $R^{2}$ & DM t-stat. \\
\hline $\operatorname{LAR}(1)$ & 0.113 & 0.919 & & 0.092 & 0.847 & & 0.065 & 0.832 & & 0.015 & 0.791 & & 0.088 & 0.778 & \\
\hline AR Rolling $60 \mathrm{~m}$ & 0.085 & 0.919 & 1.255 & 0.087 & 0.717 & $-2.200^{* *}$ & 0.028 & 0.370 & $-2.725^{* * *}$ & 0.022 & 0.130 & $-2.851^{* * *}$ & 0.073 & 0.096 & $-2.840^{* * *}$ \\
\hline AR Rolling $120 \mathrm{~m}$ & 0.092 & 0.921 & $2.240^{* *}$ & 0.064 & 0.719 & $-2.297^{* *}$ & 0.007 & 0.354 & $-2.924^{* * *}$ & 0.001 & 0.077 & $-2.903^{* * *}$ & 0.000 & 0.001 & $-2.883^{* * *}$ \\
\hline AR Recursive & 0.078 & 0.922 & $1.937^{* * *}$ & 0.065 & 0.724 & $-2.207^{* *}$ & 0.006 & 0.352 & $-2.695^{* * *}$ & 0.000 & 0.066 & $-2.528^{* * *}$ & 0.000 & 0.013 & $-2.527^{* * *}$ \\
\hline RA1 Rolling 60m & 0.137 & 0.936 & $2.513^{*}$ & 0.005 & 0.772 & $-2.660^{* *}$ & 0.003 & 0.455 & $-3.655^{* * *}$ & 0.010 & 0.188 & $-3.218^{* * *}$ & 0.163 & 0.202 & $-2.522^{* * *}$ \\
\hline RA1 Recursive & 0.872 & 0.937 & $3.105^{* * *}$ & 0.154 & 0.777 & $-1.610^{*}$ & 0.012 & 0.450 & $-3.385^{* * *}$ & 0.000 & 0.160 & $-3.374^{* * *}$ & 0.000 & 0.021 & $-3.308^{* * *}$ \\
\hline RA2 Rolling 60m & 0.296 & 0.931 & $2.151^{* *}$ & 0.049 & 0.816 & -0.466 & 0.001 & 0.616 & $-2.974^{* * *}$ & 0.000 & 0.433 & $-3.057^{* * *}$ & 0.084 & $\underline{0.271}$ & $-2.507^{* * *}$ \\
\hline RA2 Recursive & 0.054 & 0.932 & $3.359^{* * *}$ & 0.067 & 0.790 & -1.287 & 0.013 & 0.495 & $-2.443^{* * *}$ & 0.000 & 0.220 & $-2.189^{* *}$ & 0.000 & 0.026 & $-2.150^{* *}$ \\
\hline TS1 Rolling 60m & 0.030 & $\underline{0.938}$ & $2.475^{* *}$ & 0.002 & 0.778 & $-2.147^{* *}$ & 0.002 & 0.450 & $-3.733^{* * *}$ & 0.001 & 0.175 & $-3.655^{* * *}$ & 0.030 & 0.128 & $-2.784^{* * *}$ \\
\hline TS1 Recursive & 0.821 & 0.936 & $2.881^{* * *}$ & 0.237 & 0.767 & $-1.788^{*}$ & 0.036 & 0.427 & $-3.151^{* * *}$ & 0.003 & 0.154 & $-3.120^{* * *}$ & 0.000 & 0.044 & $-3.064^{* * *}$ \\
\hline TS2 Rolling 60m & 0.139 & 0.932 & $2.162^{* *}$ & 0.016 & 0.833 & 0.005 & 0.000 & 0.639 & $-3.356^{* * *}$ & 0.000 & $\underline{0.439}$ & $-3.249^{* * *}$ & 0.006 & 0.217 & $-2.759^{* * *}$ \\
\hline TS2 Recursive & 0.231 & 0.931 & $2.604^{* *}$ & 0.106 & 0.795 & -1.091 & 0.020 & 0.518 & $-2.950^{* * *}$ & 0.001 & 0.278 & $-2.807^{* * *}$ & 0.000 & 0.085 & $-2.724^{* * *}$ \\
\hline TS3 Rolling 60m & 0.156 & 0.940 & $2.732^{* *}$ & 0.012 & $\underline{0.834}$ & -0.005 & 0.000 & $\underline{0.630}$ & $-3.215^{* * *}$ & 0.000 & 0.421 & $-3.272^{* * *}$ & 0.002 & 0.217 & $-2.735^{* * *}$ \\
\hline TS3 Recursive & 0.704 & 0.937 & $2.797^{* *}$ & 0.172 & 0.800 & -0.853 & 0.021 & 0.520 & $-3.066^{* * *}$ & 0.001 & 0.278 & $-3.035^{* * *}$ & 0.000 & 0.103 & $-2.925^{* * *}$ \\
\hline Random Walk & 0.102 & 0.922 & $1.992^{* *}$ & 0.035 & 0.721 & $-2.380^{* *}$ & 0.001 & 0.341 & $-2.938^{* * *}$ & 0.000 & 0.054 & $-2.831^{* * *}$ & 0.000 & 0.023 & $-2.975^{* * *}$ \\
\hline
\end{tabular}


c) Interest rate

\begin{tabular}{|c|c|c|c|c|c|c|c|c|c|c|c|c|}
\hline & \multicolumn{3}{|c|}{$h=1 w$} & \multicolumn{3}{|c|}{$\mathrm{h}=4 \mathrm{w}$} & \multicolumn{3}{|c|}{$h=12 w$} & \multicolumn{3}{|c|}{$h=24 w$} \\
\hline & p_v & $R^{2}$ & DM t-stat. & p_v & $R^{2}$ & DM t-stat. & p_v & $R^{2}$ & DM t-stat. & p_v & $R^{2}$ & DM t-stat. \\
\hline$\underline{\operatorname{LAR}(1)}$ & 0.182 & 0.561 & & 0.101 & 0.448 & & 0.076 & 0.417 & & 0.017 & 0.396 & \\
\hline AR Rolling 60m & 0.301 & 0.497 & $-2.069^{* *}$ & 0.116 & 0.373 & -0.827 & 0.271 & 0.254 & $-1.823^{*}$ & 0.033 & 0.209 & $-2.599^{* * *}$ \\
\hline AR Rolling $120 \mathrm{~m}$ & 0.005 & 0.530 & -0.870 & 0.013 & 0.386 & -0.396 & 0.045 & $\underline{0.255}$ & $-2.206^{* *}$ & 0.070 & $\underline{0.269}$ & $-2.210^{* *}$ \\
\hline AR Recursive & 0.000 & 0.528 & -1.221 & 0.003 & 0.376 & -0.666 & 0.015 & 0.225 & $-2.460^{* * *}$ & 0.010 & 0.242 & $-2.641^{* * *}$ \\
\hline Random Walk & 0.000 & 0.535 & $-1.403^{*}$ & 0.000 & $\underline{0.390}$ & $-1.985^{* *}$ & 0.000 & 0.204 & $-3.391^{* * *}$ & 0.000 & 0.217 & $-3.562^{* * *}$ \\
\hline
\end{tabular}

\section{Notes:}

1) $h$ denotes the forecast horizon. The forecast periods are the same with Table 3 and Table 4 .

2) For each forecast horizon, we report the $p$-value of the F-test on forecast rationality, i.e., $H_{0}: \alpha=0$ and $\beta=1$, as well as the coefficient of determination $\left(R^{2}\right)$ of the Mincer-Zarnowitz regression given in Equation (5). The third column (DM t-stat.) gives the t-statistics of the Diebold-Mariano test, that is $H_{0}: \mu=0$ in the regression $e_{t, L A R}^{2}-e_{t, i}^{2}=\mu+\xi_{t}$ where $e_{t, i}$ denotes the forecast error of model i. Both tests are modified with robust Newey-West variances for heteroscedasticity and autocorrelation with the lags equal to the forecast horizon.

3) For column of $R^{2}$, the best forecast, i.e., the largest $R^{2}$ is marked in bold-face; the second best is underlined.

4) For column of the DM-stat., * denotes the significance level of $10 \%$; ** denotes significance level of $5 \%$ and $* * *$ denotes $1 \%$. 
Table 7. Forecast Comparison between the LAR and CMRC survey

a) Growth of industrial production

\begin{tabular}{|c|c|c|c|c|c|}
\hline & \multirow{2}{*}{$\frac{\text { CMRC }}{h=1 q}$} & \multicolumn{4}{|c|}{$\operatorname{LAR}(1)$} \\
\hline & & $h=1 q$ & $h=2 q$ & $h=3 q$ & $\mathrm{~h}=4 \mathrm{q}$ \\
\hline RMSE & 1.621 & 1.422 & 1.433 & 1.541 & 1.435 \\
\hline MAE & 1.099 & 1.144 & 1.095 & 1.028 & 1.006 \\
\hline $\operatorname{Std}(A E)$ & 1.194 & 0.833 & 0.907 & 1.147 & 0.994 \\
\hline Std(Err) & 1.589 & 1.422 & 1.433 & 1.541 & 1.435 \\
\hline p_value & 0.467 & 0.074 & 0.603 & 0.657 & 0.631 \\
\hline$R^{2}$ & 0.791 & 0.857 & 0.832 & 0.804 & 0.831 \\
\hline DM t-stat. & & -0.428 & -0.581 & -0.229 & -1.380 \\
\hline \multicolumn{6}{|c|}{ b) Inflation rate } \\
\hline & CMRC & \multicolumn{4}{|c|}{$\operatorname{LAR}(1)$} \\
\hline & $\mathrm{h}=1 \mathrm{q}$ & $\mathrm{h}=1 \mathrm{q}$ & $\mathrm{h}=2 \mathrm{q}$ & $h=3 q$ & $\mathrm{~h}=4 \mathrm{q}$ \\
\hline RMSE & 0.645 & 0.639 & 0.813 & 0.880 & 0.791 \\
\hline MAE & 0.477 & 0.473 & 0.664 & 0.623 & 0.568 \\
\hline $\operatorname{Std}(A E)$ & 0.445 & 0.554 & 0.610 & 0.604 & 0.551 \\
\hline Std(Err) & 0.639 & 0.799 & 0.913 & 0.880 & 0.791 \\
\hline p_value & 0.172 & 0.115 & 0.100 & 0.105 & 0.828 \\
\hline$R^{2}$ & 0.930 & 0.933 & 0.887 & 0.864 & 0.883 \\
\hline DM t-stat. & & 1.203 & 1.433 & 1.381 & 1.588 \\
\hline
\end{tabular}

Notes:

1) $\mathrm{h}$ denotes the forecast horizon. The column $\mathrm{CMRC}$ denotes the one-quarter horizon forecast with the CMRC data. We transform the 3-, 6-, 9- and 12-month horizon monthly forecast of LAR into 1-, 2-, 3- and 4-quarter horizon quarterly forecast according to the equations (10) and (17). For simplifying the comparison, the data intervals are uniformly chosen as the same, from 2006:Q1 to 2014:Q1, for CMRC survey data, IP growth, and inflation rate, a total of 33 quarters.

2) In each forecast horizon of LAR(1), the bold-face number indicates the better of the pair of a LAR h-step ahead forecast and the CMRC survey 1-step ahead forecast for the same targeting forecast interval for each measure of RMSE, MAE, $\operatorname{Std}(\mathrm{AE}), \operatorname{Std}(\mathrm{Err})$ and $R^{2}$.

3) Both the p-value and $R^{2}$ report the results of the Mincer-Zarnowitz regression for CMRC and LAR(1) model with different forecast horizons. The last row, DM t-stat. reports the test $H_{0}: \mu=0$ in the regression $e_{t, L A R(h=i)}^{2}-e_{t, C M R C}^{2}=\mu+\xi_{t}$ where $e_{t, L A R(h=i)}$ represents the $\operatorname{LAR}(1)$ forecast with horizon $\mathrm{h}=1,2,3$, 4. Both tests are modified with robust Newey-West variances for heteroscedasticity and autocorrelation with the lags equal to the forecast horizon. 
Table 8. Average lengths of homogeneous intervals detected by LAR

\begin{tabular}{ccccc}
\hline & $\mathrm{h}=1 \mathrm{~m}$ & $\mathrm{~h}=3 \mathrm{~m}$ & $\mathrm{~h}=6 \mathrm{~m}$ & $\mathrm{~h}=12 \mathrm{~m}$ \\
\hline IP growth & 32 & 16 & 14 & 16 \\
Inflation rate & 81 & 37 & 32 & 34 \\
\hline Interest rate & $\mathrm{h}=1 \mathrm{w}$ & $\mathrm{h}=4 \mathrm{w}$ & $\mathrm{h}=12 \mathrm{w}$ & $\mathrm{h}=24 \mathrm{w}$ \\
\hline & 70 & 50 & 40 & 36 \\
\hline
\end{tabular}

Notes: $h$ denotes the forecast horizon. 
Table 9. Robustness check with subsample forecast for IP growth and inflation rate

a) Initial samples of estimation and periods of forecast comparison

\begin{tabular}{ccccc}
\hline & \multicolumn{2}{c}{ The maximal interval of the initial sample } & \multicolumn{2}{c}{ Out-of-sample forecast comparison } \\
\hline $\begin{array}{c}\text { Forecast horizon } h \\
\text { (month) }\end{array}$ & $\begin{array}{c}\text { Dependent variable } \\
\text { interval }\end{array}$ & $\begin{array}{c}\text { Explanatory variable } \\
\text { in lag term }\end{array}$ & $\begin{array}{c}\text { Forecast } \\
\text { interval }\end{array}$ & $\begin{array}{c}\text { Forecast } \\
\text { periods }\end{array}$ \\
\hline 1 & $1998: 02-2007: 12$ & $1998: 01-2007: 11$ & $2008: 01-2014: 03$ & 75 \\
3 & $1998: 04-2008: 02$ & $1998: 01-2007: 11$ & $2008: 03-2014: 03$ & 73 \\
6 & $1998: 07-2008: 05$ & $1998: 01-2007: 11$ & $2008: 06-2014: 03$ & 70 \\
9 & $1998: 10-2008: 08$ & $1998: 01-2007: 11$ & $2008: 09-2014: 03$ & 67 \\
12 & $1998: 01-2008: 11$ & $1998: 01-2007: 11$ & $2008: 12-2014: 03$ & 64 \\
\hline
\end{tabular}


b) Out-of-Sample forecast comparison: RMSE and MAE

IP growth

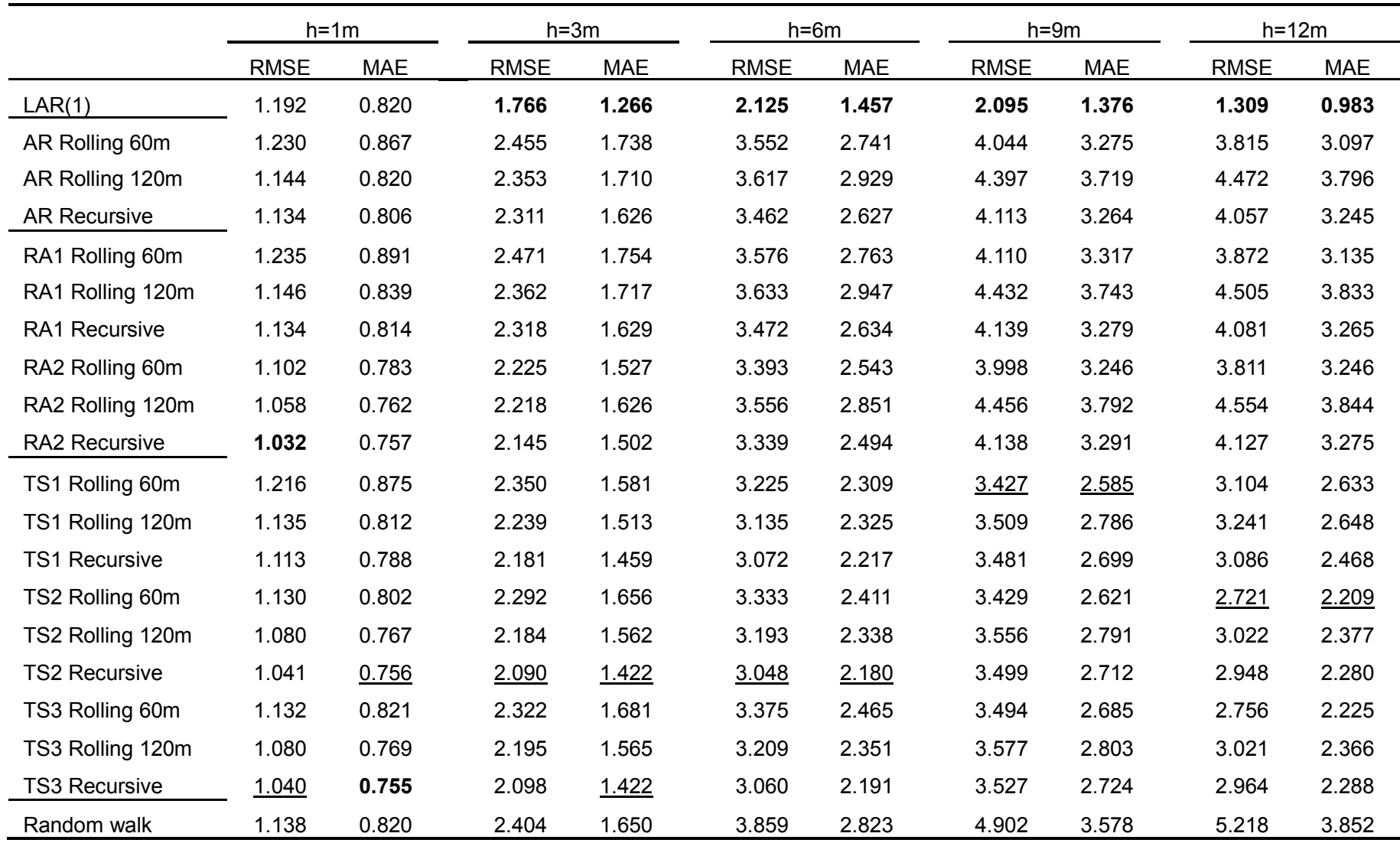

Inflation

\begin{tabular}{|c|c|c|c|c|c|c|c|c|c|c|}
\hline & \multicolumn{2}{|c|}{$\mathrm{h}=1 \mathrm{~m}$} & \multicolumn{2}{|c|}{$h=3 m$} & \multicolumn{2}{|c|}{$\mathrm{h}=6 \mathrm{~m}$} & \multicolumn{2}{|c|}{$\mathrm{h}=9 \mathrm{~m}$} & \multicolumn{2}{|c|}{$h=12 m$} \\
\hline & RMSE & MAE & RMSE & MAE & RMSE & MAE & RMSE & MAE & RMSE & MAE \\
\hline $\operatorname{LAR}(1)$ & 0.710 & 0.536 & 0.929 & 0.686 & 1.100 & 0.811 & 1.208 & 0.818 & 0.904 & 0.637 \\
\hline AR Rolling 60m & 0.706 & 0.528 & 1.359 & 1.082 & 2.104 & 1.655 & 2.274 & 1.705 & 1.893 & 1.557 \\
\hline AR Rolling $120 \mathrm{~m}$ & 0.696 & 0.523 & 1.356 & 1.080 & 2.210 & 1.725 & 2.630 & 2.022 & 2.556 & 1.944 \\
\hline AR Recursive & 0.696 & 0.523 & 1.360 & 1.094 & 2.240 & 1.775 & 2.700 & 2.118 & 2.688 & 2.076 \\
\hline RA1 Rolling 60m & 0.662 & 0.524 & 1.253 & 1.062 & 2.041 & 1.628 & 2.279 & 1.722 & 1.801 & 1.303 \\
\hline RA1 Rolling 120m & 0.669 & 0.509 & 1.227 & 1.018 & 2.011 & 1.611 & 2.377 & 1.792 & 2.295 & 1.711 \\
\hline RA1 Recursive & 0.652 & 0.489 & 1.198 & 0.994 & 2.027 & 1.661 & 2.490 & 2.018 & 2.511 & 2.119 \\
\hline RA2 Rolling 60m & 0.634 & 0.506 & 1.048 & 0.887 & 1.730 & 1.423 & 2.002 & 1.571 & 1.717 & 1.322 \\
\hline RA2 Rolling 120m & 0.641 & 0.507 & 1.099 & 0.945 & 1.808 & 1.466 & 2.238 & 1.758 & 2.303 & 1.719 \\
\hline RA2 Recursive & 0.627 & 0.487 & 1.059 & 0.914 & 1.786 & 1.426 & 2.273 & 1.841 & 2.453 & 2.031 \\
\hline TS1 Rolling $60 \mathrm{~m}$ & 0.661 & 0.510 & 1.257 & 1.055 & 2.065 & 1.626 & 2.277 & 1.725 & 1.831 & 1.382 \\
\hline TS1 Rolling 120m & 0.663 & 0.507 & 1.254 & 1.079 & 2.082 & 1.715 & 2.418 & 1.836 & 2.237 & 1.654 \\
\hline TS1 Recursive & 0.650 & 0.487 & 1.201 & 1.000 & 2.018 & 1.643 & 2.432 & 1.948 & 2.364 & 1.999 \\
\hline TS2 Rolling $60 \mathrm{~m}$ & $\underline{0.616}$ & 0.483 & $\underline{0.968}$ & $\underline{0.814}$ & 1.637 & 1.368 & $\underline{1.898}$ & 1.549 & 1.696 & 1.295 \\
\hline TS2 Rolling 120m & 0.613 & 0.475 & 1.005 & 0.834 & 1.767 & 1.440 & 2.215 & 1.710 & 2.236 & 1.651 \\
\hline TS2 Recursive & $\underline{0.616}$ & $\underline{0.478}$ & 1.025 & 0.866 & 1.789 & 1.447 & 2.289 & 1.861 & 2.379 & 1.991 \\
\hline TS3 Rolling 60m & 0.633 & 0.489 & 0.995 & 0.827 & 1.687 & 1.404 & 1.976 & 1.618 & 1.815 & 1.435 \\
\hline TS3 Rolling 120m & 0.638 & 0.486 & 1.007 & 0.848 & 1.754 & 1.444 & 2.190 & 1.671 & 2.215 & 1.618 \\
\hline TS3 Recursive & 0.634 & 0.488 & 1.031 & 0.865 & 1.797 & 1.495 & 2.309 & 1.894 & 2.409 & 2.045 \\
\hline Random walk & 0.699 & 0.524 & 1.413 & 1.125 & 2.504 & 2.005 & 3.439 & 2.738 & 4.137 & 3.295 \\
\hline
\end{tabular}




\section{c) Out-of-Sample forecast comparison: $\operatorname{Std}(\mathrm{AE})$ and $\operatorname{Std}(\mathrm{Err})$}

IP growth

\begin{tabular}{|c|c|c|c|c|c|c|c|c|c|c|}
\hline & \multicolumn{2}{|c|}{$\mathrm{h}=1 \mathrm{~m}$} & \multicolumn{2}{|c|}{$h=3 m$} & \multicolumn{2}{|c|}{$\mathrm{h}=6 \mathrm{~m}$} & \multicolumn{2}{|c|}{$\mathrm{h}=9 \mathrm{~m}$} & \multicolumn{2}{|c|}{$h=12 m$} \\
\hline & $\operatorname{Std}(A E)$ & Std(Err) & $\operatorname{Std}(A E)$ & Std(Err) & $\operatorname{Std}(A E)$ & Std(Err) & $\operatorname{Std}(A E)$ & Std(Err) & $\operatorname{Std}(A E)$ & Std(Err) \\
\hline $\operatorname{LAR}(1)$ & 0.861 & 1.192 & 1.204 & 1.766 & 1.546 & 2.125 & 1.580 & 2.095 & 0.864 & 1.309 \\
\hline AR Rolling 60m & 0.879 & 1.217 & 1.764 & 2.388 & 2.346 & 3.219 & 2.372 & 3.279 & 2.228 & 2.515 \\
\hline AR Rolling 120m & 0.799 & 1.120 & 1.634 & 2.238 & 2.278 & 3.259 & 2.589 & 3.779 & 2.365 & 3.718 \\
\hline AR Recursive & 0.798 & 1.120 & 1.664 & 2.249 & 2.364 & 3.283 & 2.758 & 3.822 & 2.619 & 3.742 \\
\hline RA1 Rolling 60m & 0.868 & 1.224 & 1.770 & 2.403 & 2.340 & 3.236 & 2.427 & 3.329 & 2.272 & 2.537 \\
\hline RA1 Rolling 120m & 0.787 & 1.121 & 1.637 & 2.244 & 2.283 & 3.270 & 2.580 & 3.805 & 2.367 & 3.743 \\
\hline RA1 Recursive & 0.792 & 1.120 & 1.665 & 2.255 & 2.373 & 3.291 & 2.760 & 3.845 & 2.633 & 3.764 \\
\hline RA2 Rolling 60m & 0.804 & 1.044 & 1.619 & 2.032 & 2.246 & 2.788 & 2.333 & 3.241 & 1.996 & 3.047 \\
\hline RA2 Rolling 120m & 0.735 & 1.017 & $\underline{1.508}$ & 2.041 & 2.144 & 3.065 & 2.635 & 3.815 & 2.443 & 3.900 \\
\hline RA2 Recursive & 0.708 & $\underline{1.011}$ & 1.531 & 2.054 & 2.220 & 3.100 & 2.760 & 3.824 & 2.694 & 3.829 \\
\hline TS1 Rolling 60m & 0.846 & 1.214 & 1.739 & 2.330 & 2.251 & 3.031 & 2.250 & 2.910 & 1.644 & $\underline{2.275}$ \\
\hline TS1 Rolling 120m & 0.793 & 1.128 & 1.651 & 2.205 & $\underline{2.103}$ & 2.945 & $\underline{2.134}$ & 3.127 & 1.869 & 2.724 \\
\hline TS1 Recursive & 0.786 & 1.105 & 1.621 & 2.136 & 2.127 & 2.907 & 2.234 & 3.165 & 1.879 & 2.660 \\
\hline TS2 Rolling 60m & 0.796 & 1.004 & 1.585 & $\underline{2.005}$ & 2.302 & $\underline{2.693}$ & 2.212 & 2.887 & 1.590 & 2.370 \\
\hline TS2 Rolling 120m & 0.778 & 1.037 & 1.572 & 2.070 & 2.175 & 2.866 & 2.203 & 3.211 & 1.883 & 2.714 \\
\hline TS2 Recursive & 0.731 & 1.024 & 1.532 & 2.018 & 2.130 & 2.839 & 2.239 & 3.195 & 1.868 & 2.590 \\
\hline TS3 Rolling 60m & 0.779 & 1.016 & 1.601 & 2.020 & 2.305 & 2.714 & 2.236 & 2.941 & 1.626 & 2.418 \\
\hline TS3 Rolling 120m & 0.767 & 1.040 & 1.584 & 2.079 & 2.183 & 2.878 & 2.223 & 3.230 & 1.887 & 2.715 \\
\hline TS3 Recursive & 0.727 & 1.022 & 1.552 & 2.024 & 2.136 & 2.848 & 2.265 & 3.221 & 1.884 & 2.606 \\
\hline Random walk & 0.793 & 1.132 & 1.763 & 2.384 & 2.632 & 3.812 & 3.351 & 4.831 & 3.556 & 5.151 \\
\hline \multicolumn{11}{|c|}{ Inflation } \\
\hline & \multicolumn{2}{|c|}{$\mathrm{h}=1 \mathrm{~m}$} & \multicolumn{2}{|c|}{$\mathrm{h}=3 \mathrm{~m}$} & \multicolumn{2}{|c|}{$\mathrm{h}=6 \mathrm{~m}$} & \multicolumn{2}{|c|}{$\mathrm{h}=9 \mathrm{~m}$} & \multicolumn{2}{|c|}{$h=12 m$} \\
\hline & $\operatorname{Std}(A E)$ & Std(Err) & $\operatorname{Std}(A E)$ & Std(Err) & $\operatorname{Std}(A E)$ & Std(Err) & $\operatorname{Std}(A E)$ & Std(Err) & $\operatorname{Std}(A E)$ & $\operatorname{Std}(E r r)$ \\
\hline $\operatorname{LAR}(1)$ & 0.465 & 0.710 & 0.624 & 0.929 & 0.735 & 1.100 & 0.886 & 1.208 & 0.642 & 0.904 \\
\hline AR Rolling 60m & 0.468 & 0.703 & 0.838 & 1.340 & 1.325 & 2.048 & 1.504 & 2.190 & 1.138 & 1.820 \\
\hline AR Rolling 120m & 0.459 & 0.692 & 0.827 & 1.334 & 1.382 & 2.170 & 1.681 & 2.602 & 1.663 & 2.554 \\
\hline AR Recursive & 0.460 & 0.695 & 0.826 & 1.352 & 1.397 & 2.228 & 1.695 & 2.698 & 1.759 & 2.675 \\
\hline RA1 Rolling 60m & 0.418 & 0.635 & 0.668 & 1.212 & 1.284 & 2.024 & 1.512 & 2.278 & 1.248 & 1.800 \\
\hline RA1 Rolling 120m & 0.435 & 0.646 & 0.693 & 1.213 & 1.236 & 2.006 & 1.605 & 2.369 & 1.546 & 2.241 \\
\hline RA1 Recursive & 0.432 & 0.635 & 0.674 & 1.185 & 1.217 & 2.014 & 1.557 & 2.443 & 1.565 & 2.335 \\
\hline RA2 Rolling 60m & 0.399 & 0.627 & 0.559 & 1.026 & 1.012 & 1.718 & 1.254 & 2.000 & 1.104 & 1.716 \\
\hline RA2 Rolling 120m & 0.404 & 0.634 & 0.560 & 1.083 & 1.117 & 1.797 & 1.453 & 2.219 & 1.568 & 2.262 \\
\hline RA2 Recursive & 0.400 & 0.624 & $\underline{0.534}$ & 1.051 & 1.105 & 1.776 & 1.405 & 2.231 & 1.518 & 2.326 \\
\hline TS1 Rolling 60m & 0.421 & 0.647 & 0.705 & 1.237 & 1.296 & 2.063 & 1.493 & 2.277 & 1.202 & 1.831 \\
\hline TS1 Rolling 120m & 0.429 & 0.650 & 0.658 & 1.247 & 1.189 & 2.082 & 1.601 & 2.415 & 1.506 & 2.197 \\
\hline TS1 Recursive & 0.432 & 0.632 & 0.676 & 1.186 & 1.241 & 2.003 & 1.568 & 2.384 & 1.600 & 2.194 \\
\hline TS2 Rolling 60m & 0.383 & 0.616 & 0.532 & $\underline{0.967}$ & $\underline{0.902}$ & $\underline{1.636}$ & 1.110 & 1.895 & 1.095 & 1.689 \\
\hline TS2 Rolling 120m & $\underline{0.388}$ & 0.613 & 0.561 & 1.005 & 1.040 & 1.764 & 1.409 & 2.215 & 1.509 & 2.226 \\
\hline TS2 Recursive & 0.400 & $\underline{0.614}$ & 0.548 & 1.017 & 1.083 & 1.777 & 1.407 & 2.243 & 1.492 & 2.257 \\
\hline TS3 Rolling 60m & 0.401 & 0.626 & 0.564 & 0.989 & 0.941 & 1.686 & 1.151 & 1.970 & 1.113 & 1.815 \\
\hline TS3 Rolling 120m & 0.413 & 0.623 & 0.543 & 1.000 & 1.000 & 1.754 & 1.425 & 2.187 & 1.513 & 2.165 \\
\hline TS3 Recursive & 0.415 & $\underline{0.614}$ & 0.561 & 1.004 & 1.042 & 1.768 & 1.389 & 2.229 & 1.497 & 2.197 \\
\hline Random walk & 0.462 & 0.697 & 0.874 & 1.397 & 1.584 & 2.464 & 2.160 & 3.384 & 2.550 & 4.077 \\
\hline
\end{tabular}




\section{d) Out-of-Sample forecast comparison: MZ regression and DM test}

IP growth

\begin{tabular}{|c|c|c|c|c|c|c|c|c|c|c|c|c|c|c|c|}
\hline & \multicolumn{3}{|c|}{$\mathrm{h}=1 \mathrm{~m}$} & \multicolumn{3}{|c|}{$\mathrm{h}=3 \mathrm{~m}$} & \multicolumn{3}{|c|}{$\mathrm{h}=6 \mathrm{~m}$} & \multicolumn{3}{|c|}{$\mathrm{h}=9 \mathrm{~m}$} & \multicolumn{3}{|c|}{$h=12 m$} \\
\hline & p_v & $R^{2}$ & DM t-stat. & p_v & $R^{2}$ & DM t-stat. & p_v & $R^{2}$ & DM t-stat. & p_v & $R^{2}$ & DM t-stat. & p_v & $R^{2}$ & DM t-stat \\
\hline$\underline{\operatorname{LAR}(1)}$ & 0.186 & 0.866 & & 0.017 & 0.715 & & 0.000 & 0.625 & & 0.000 & 0.572 & & 0.195 & 0.819 & \\
\hline AR Rolling $60 \mathrm{~m}$ & 0.161 & 0.863 & -0.470 & 0.029 & 0.494 & -1.491 & 0.031 & 0.081 & $-2.281^{* *}$ & 0.050 & 0.001 & $-2.140^{\star *}$ & 0.000 & 0.331 & $-2.460^{\star * *}$ \\
\hline AR Rolling $120 \mathrm{~m}$ & 0.239 & 0.880 & 1.364 & 0.044 & 0.526 & $-1.627^{*}$ & 0.003 & 0.072 & $-3.088^{* * *}$ & 0.000 & 0.060 & $-3.180^{* * *}$ & 0.000 & 0.360 & $-3.305^{\star * *}$ \\
\hline AR Recursive & 0.378 & 0.880 & 1.512 & 0.052 & 0.525 & -1.477 & 0.010 & 0.080 & $-2.602^{* * *}$ & 0.004 & 0.029 & $-2.536^{\star * *}$ & 0.004 & 0.145 & $-2.526^{* * *}$ \\
\hline RA1 Rolling 60m & 0.145 & 0.862 & -0.499 & 0.026 & 0.489 & -1.531 & 0.027 & 0.078 & $-2.311^{\star *}$ & 0.042 & 0.000 & $-2.128^{\star *}$ & 0.000 & 0.306 & $-2.487^{\star \star \star}$ \\
\hline RA1 Rolling 120m & 0.231 & 0.879 & 1.438 & 0.041 & 0.523 & $-1.655^{*}$ & 0.002 & 0.070 & $-3.134^{\star \star \star}$ & 0.000 & 0.062 & $-3.159^{\star * *}$ & 0.000 & 0.358 & $-3.299^{* * *}$ \\
\hline RA1 Recursive & 0.375 & 0.880 & $1.651^{*}$ & 0.049 & 0.523 & -1.499 & 0.009 & 0.079 & $-2.624^{\star \star \star}$ & 0.003 & 0.031 & $-2.514^{\star \star \star}$ & 0.003 & 0.150 & $-2.519^{* * *}$ \\
\hline RA2 Rolling 60m & 0.001 & 0.907 & 1.022 & 0.000 & 0.679 & -0.940 & 0.003 & 0.330 & $-1.932^{* *}$ & 0.045 & 0.017 & $-2.101^{* *}$ & 0.014 & 0.047 & $-2.830^{* * *}$ \\
\hline RA2 Rolling 120m & 0.002 & 0.915 & 1.150 & 0.000 & 0.666 & -1.215 & 0.000 & 0.231 & $-3.366^{\star \star *}$ & 0.000 & 0.036 & $-3.178^{* * *}$ & 0.000 & 0.400 & $-3.213^{* * *}$ \\
\hline RA2 Recursive & 0.029 & $\underline{0.910}$ & $1.711^{*}$ & 0.001 & 0.636 & -1.038 & 0.002 & 0.204 & $-2.651^{* * *}$ & 0.006 & 0.005 & $-2.464^{* \star *}$ & 0.002 & 0.161 & $-2.452^{* \star *}$ \\
\hline TS1 Rolling 60m & 0.086 & 0.867 & -0.072 & 0.001 & 0.538 & -1.321 & 0.036 & 0.206 & $-1.866^{*}$ & 0.066 & $\underline{0.208}$ & $-1.598^{*}$ & 0.000 & $\underline{0.527}$ & $-3.199^{* * *}$ \\
\hline TS1 Rolling 120m & 0.471 & 0.879 & 1.294 & 0.031 & 0.555 & -1.247 & 0.014 & 0.220 & $-2.351^{* *}$ & 0.047 & 0.143 & $-2.012^{\star *}$ & 0.002 & 0.281 & $-2.748^{* * *}$ \\
\hline TS1 Recursive & 0.602 & 0.882 & $2.098^{* *}$ & 0.180 & 0.562 & -1.060 & 0.094 & 0.199 & $-2.072^{* *}$ & 0.183 & 0.076 & $-1.820^{*}$ & 0.056 & 0.247 & $-2.110^{\star *}$ \\
\hline TS2 Rolling 60m & 0.000 & 0.909 & 0.653 & 0.000 & $\underline{0.683}$ & -1.229 & 0.001 & $\underline{0.395}$ & $-1.927^{\star *}$ & 0.062 & 0.206 & $-1.682^{*}$ & 0.012 & 0.433 & $-2.517^{\star * *}$ \\
\hline TS2 Rolling 120m & 0.004 & $\underline{0.910}$ & 0.929 & 0.000 & 0.674 & -1.017 & 0.000 & 0.367 & $-2.097^{\star *}$ & 0.025 & 0.140 & $-2.073^{\star *}$ & 0.110 & 0.252 & $-2.250^{\star *}$ \\
\hline TS2 Recursive & 0.088 & 0.905 & $1.721^{*}$ & 0.010 & 0.636 & -0.817 & 0.025 & 0.271 & $-2.029^{* *}$ & 0.188 & 0.066 & $-1.822^{*}$ & 0.026 & 0.264 & $-1.931^{* *}$ \\
\hline TS3 Rolling 60m & 0.000 & 0.909 & 0.653 & 0.000 & 0.678 & -1.296 & 0.000 & 0.389 & $-1.978^{* *}$ & 0.063 & 0.186 & $-1.709^{*}$ & 0.014 & 0.417 & $-2.538^{* * *}$ \\
\hline TS3 Rolling 120m & 0.003 & $\underline{0.910}$ & 0.937 & 0.000 & 0.672 & -1.035 & 0.000 & 0.365 & $-2.110^{\star *}$ & 0.025 & 0.136 & $-2.058^{\star *}$ & 0.110 & 0.253 & $-2.215^{\star *}$ \\
\hline TS3 Recursive & 0.085 & 0.905 & $1.793^{*}$ & 0.011 & 0.634 & -0.833 & 0.024 & 0.269 & $-2.042^{* *}$ & 0.181 & 0.061 & $-1.808^{*}$ & 0.030 & 0.257 & $-1.920^{\star *}$ \\
\hline Random Walk & 0.208 & 0.881 & 1.218 & 0.000 & 0.525 & $-1.780^{*}$ & 0.000 & 0.081 & $-2.716^{\star \star \star}$ & 0.000 & 0.019 & $-2.385^{\star *}$ & 0.000 & 0.104 & $-2.175^{\star *}$ \\
\hline
\end{tabular}


Inflation

\begin{tabular}{|c|c|c|c|c|c|c|c|c|c|c|c|c|c|c|c|}
\hline & \multicolumn{3}{|c|}{$h=1 m$} & \multicolumn{3}{|c|}{$\mathrm{h}=3 \mathrm{~m}$} & \multicolumn{3}{|c|}{$\mathrm{h}=6 \mathrm{~m}$} & \multicolumn{3}{|c|}{$h=9 m$} & \multicolumn{3}{|c|}{$h=12 m$} \\
\hline & p_v & $R^{2}$ & DM t-stat. & p_v & $R^{2}$ & DM t-stat. & p_v & $R^{2}$ & DM t-stat. & p_v & $R^{2}$ & DM t-stat & p_v & $R^{2}$ & DM t-stat. \\
\hline$\underline{\operatorname{LAR}(1)}$ & 0.004 & 0.923 & & 0.004 & 0.888 & & 0.047 & 0.826 & & 0.010 & 0.736 & & 0.009 & 0.836 & \\
\hline AR Rolling $60 \mathrm{~m}$ & 0.231 & 0.920 & 1.483 & 0.129 & 0.705 & $-1.825^{*}$ & 0.032 & 0.233 & $-1.967^{\star \star}$ & 0.016 & 0.002 & $-1.923^{\star *}$ & 0.571 & 0.270 & $-2.400^{\star *}$ \\
\hline AR Rolling $120 \mathrm{~m}$ & 0.409 & 0.921 & $2.040^{\star \star}$ & 0.204 & 0.702 & $-1.938^{\star \star}$ & 0.008 & 0.209 & $-2.176^{\star *}$ & 0.000 & 0.005 & $-2.080^{\star *}$ & 0.000 & 0.204 & $-2.096^{\star \star}$ \\
\hline AR Recursive & 0.397 & 0.921 & $1.978^{\star \star}$ & 0.166 & 0.702 & $-2.039^{\star \star}$ & 0.003 & 0.214 & $-2.302^{\star *}$ & 0.000 & 0.002 & $-2.216^{\star \star}$ & 0.000 & 0.246 & $-2.292^{\star \star}$ \\
\hline RA1 Rolling 60m & 0.000 & 0.939 & 1.302 & 0.000 & 0.790 & $-2.940^{\star \star *}$ & 0.002 & 0.358 & $-3.345^{\star * *}$ & 0.004 & 0.044 & $-2.775^{\star \star *}$ & 0.996 & 0.254 & $-2.434^{\star \star *}$ \\
\hline RA1 Rolling 120m & 0.024 & 0.931 & 1.191 & 0.242 & 0.751 & $-2.075^{\star \star}$ & 0.031 & 0.296 & $-2.625^{\star \star \star}$ & 0.006 & 0.022 & $-2.410^{\star *}$ & 0.038 & 0.010 & $-2.363^{\star \star}$ \\
\hline RA1 Recursive & 0.059 & 0.933 & 1.575 & 0.261 & 0.761 & $-1.958^{\star \star}$ & 0.018 & 0.307 & $-2.863^{\star \star \star}$ & 0.000 & 0.026 & $-2.950^{\star \star *}$ & 0.000 & 0.005 & $-3.225^{\star * *}$ \\
\hline RA2 Rolling 60m & 0.230 & 0.935 & $1.641^{*}$ & 0.020 & 0.830 & -0.814 & 0.000 & 0.587 & $-3.116^{\star \star *}$ & 0.000 & 0.384 & $-2.872^{\star \star \star}$ & 0.196 & 0.397 & $-2.777^{\star \star \star}$ \\
\hline RA2 Rolling $120 \mathrm{~m}$ & 0.373 & 0.933 & 1.581 & 0.167 & 0.801 & -1.224 & 0.004 & 0.498 & $-2.811^{* * *}$ & 0.000 & 0.275 & $-2.807^{* * *}$ & 0.000 & 0.165 & $-2.276^{\star *}$ \\
\hline RA2 Recursive & 0.655 & 0.935 & $2.029^{* *}$ & 0.467 & 0.806 & -0.941 & 0.029 & 0.471 & $-2.585^{\star * *}$ & 0.000 & 0.237 & $-3.053^{* * *}$ & 0.000 & 0.145 & $-3.062^{\star * *}$ \\
\hline TS1 Rolling 60m & 0.000 & $\underline{0.938}$ & 1.326 & 0.000 & 0.788 & $-2.361^{* *}$ & 0.001 & 0.372 & $-3.317^{* * *}$ & 0.001 & 0.060 & $-3.242^{* * *}$ & 0.861 & 0.239 & $-2.540^{* * *}$ \\
\hline TS1 Rolling 120m & 0.001 & 0.933 & 1.340 & 0.015 & 0.766 & $-2.954^{\star \star *}$ & 0.003 & 0.311 & $-3.149^{\star \star \star}$ & 0.002 & 0.022 & $-2.614^{\star \star \star}$ & 0.051 & 0.025 & $-2.363^{\star \star}$ \\
\hline TS1 Recursive & 0.017 & 0.934 & $1.636^{*}$ & 0.185 & 0.764 & $-2.046^{* *}$ & 0.026 & 0.299 & $-2.714^{* * *}$ & 0.001 & 0.024 & $-2.731^{* * *}$ & 0.001 & 0.028 & $-3.038^{\star * *}$ \\
\hline TS2 Rolling 60m & 0.543 & $\underline{0.938}$ & $1.973^{\star *}$ & 0.026 & $\underline{0.853}$ & -0.275 & 0.000 & $\underline{0.636}$ & $-3.754^{* * *}$ & 0.000 & $\underline{0.422}$ & $-3.047^{* * *}$ & 0.305 & $\underline{0.406}$ & $-2.660^{* * *}$ \\
\hline TS2 Rolling 120m & 0.625 & $\underline{0.938}$ & $2.195^{\star *}$ & 0.052 & 0.839 & -0.628 & 0.000 & 0.527 & $-3.040^{\star \star *}$ & 0.000 & 0.268 & $-2.672^{\star \star \star}$ & 0.000 & 0.177 & $-2.267^{\star \star}$ \\
\hline TS2 Recursive & 0.462 & $\underline{0.938}$ & $2.143^{\star *}$ & 0.135 & 0.827 & -0.725 & 0.008 & 0.498 & $-2.752^{\star \star *}$ & 0.000 & 0.248 & $-3.095^{\star \star \star}$ & 0.000 & 0.149 & $-3.059^{\star \star *}$ \\
\hline TS3 Rolling 60m & 0.014 & $\underline{0.938}$ & $1.803^{*}$ & 0.002 & $\underline{0.853}$ & -0.442 & 0.000 & 0.615 & $-3.558^{\star * *}$ & 0.000 & 0.378 & $-3.188^{\star * \star}$ & 0.130 & 0.343 & $-3.094^{* * *}$ \\
\hline TS3 Rolling 120m & 0.003 & $\underline{0.938}$ & $1.649^{*}$ & 0.006 & 0.844 & -0.596 & 0.000 & 0.530 & $-3.143^{* * *}$ & 0.000 & 0.267 & $-2.713^{\star \star *}$ & 0.000 & 0.176 & $-2.398^{\star \star}$ \\
\hline TS3 Recursive & 0.011 & $\underline{0.938}$ & $1.676^{*}$ & 0.045 & 0.832 & -0.718 & 0.005 & 0.501 & $-2.898^{\star \star *}$ & 0.000 & 0.247 & $-3.402^{\star \star \star}$ & 0.000 & 0.161 & $-3.615^{\star \star \star}$ \\
\hline Random Walk & 0.288 & 0.922 & $1.911^{*}$ & 0.059 & 0.699 & $-2.180^{\star *}$ & 0.000 & 0.212 & $-2.339^{\star \star}$ & 0.000 & 0.001 & $-2.213^{\star \star}$ & 0.000 & 0.219 & $-2.184^{\star *}$ \\
\hline
\end{tabular}

\section{Notes:}

1) For each forecast horizon, we report the $p$-value of the F-test on forecast rationality, i.e., $H_{0}: \alpha=0$ and $\beta=1$, as well as the coefficient of determination ( $R^{2}$ ) of the Mincer-Zarnowitz regression given in Equation (5). The third column (DM t-stat.) gives the t-statistics of the Diebold-Mariano test. Both tests are modified with robust Newey-West variances for heteroscedasticity and autocorrelation with the lags equal to the forecast horizon.

2) For column of $R^{2}$, the best forecast, i.e., the largest $R^{2}$ is marked in bold-face; the second best is underlined.

3) For column of the DM-stat., * denotes the significance level of $10 \%$; ** denotes significance level of $5 \%$ and $* * *$ denotes $1 \%$. 
Figure 1. Plot of the three macroeconomic variables
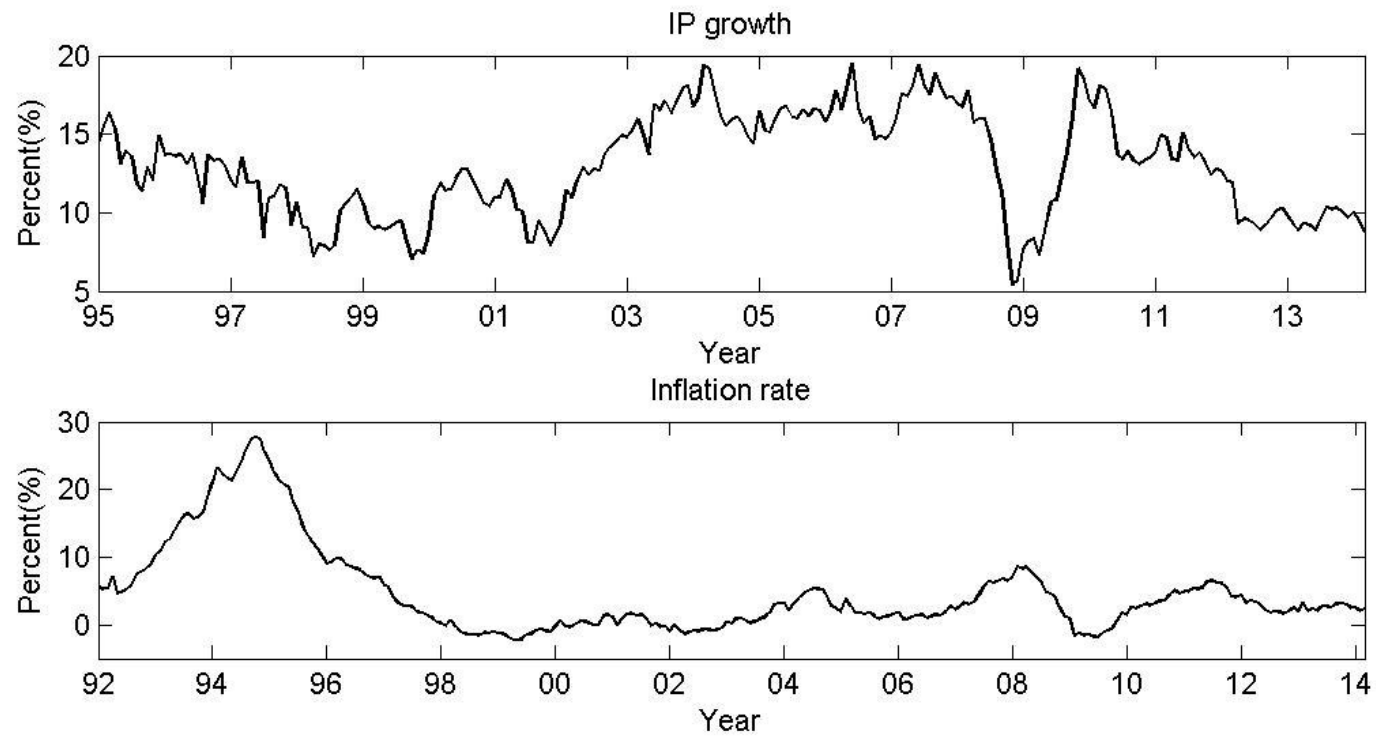

Interest rate

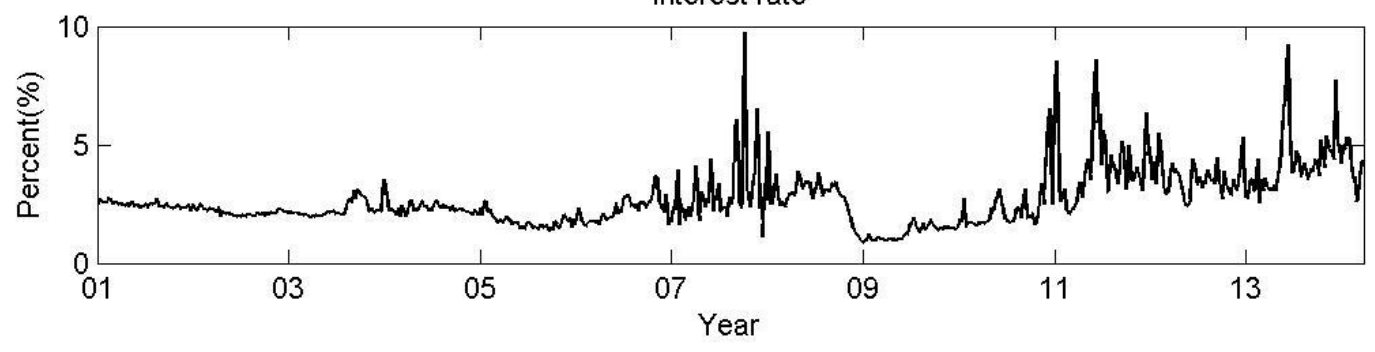

\section{Notes:}

The first row is monthly data of the growth rate of industrial production from 1995:1 to 2014:3; the second row is the monthly CPI inflation rate from 1992:1 to 2014:3; the third row is the selected interest rate, the weekly 7-day Chibor (China Interbank Offered Rate), taken from the weighted average closing rate of the last trading day of a week, from January 2001 to March 2014. All data are from CEIC China Economic and Industry Database. 
Figure 2. Autocorrelation functions of the three variables

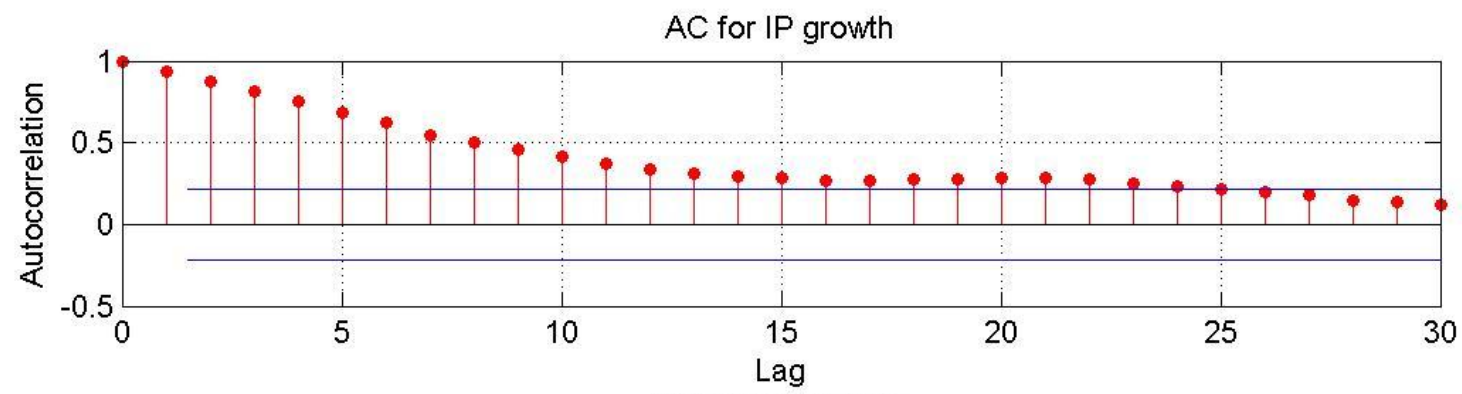

AC for Inflation rate

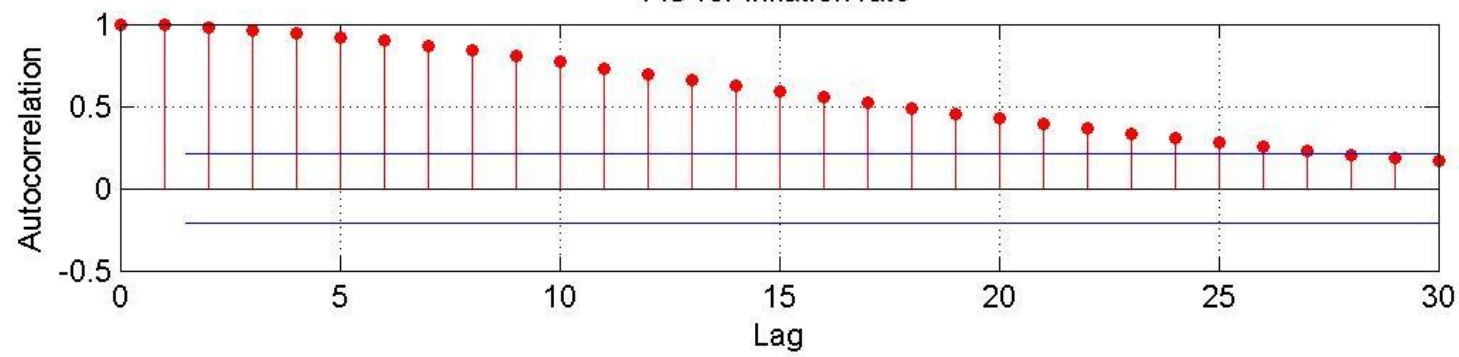

$A C$ for Interest rate

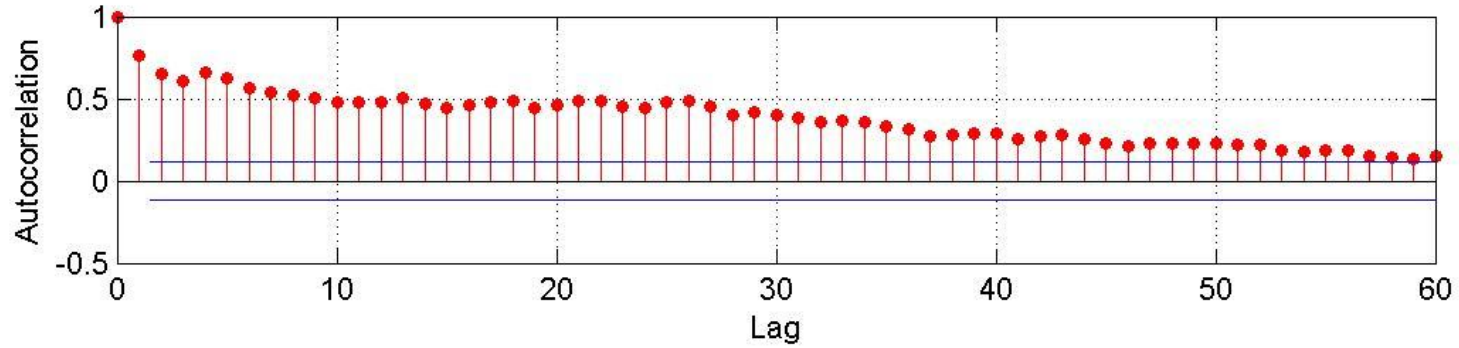


Figure 3. Plots of the realized data with forecasts of LAR and representative comparing models
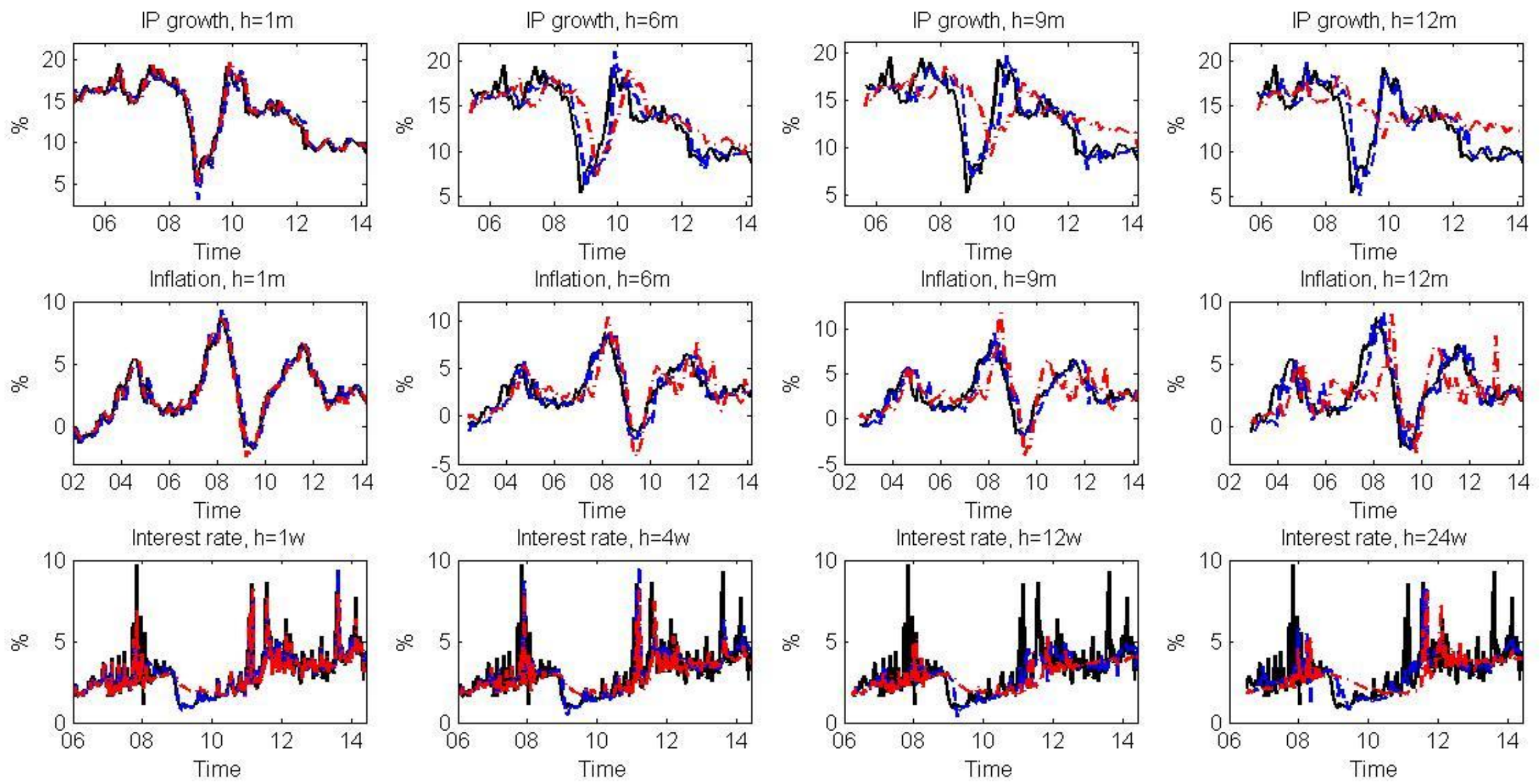

Notes: The solid lines indicate the actual data; dashed lines are the LAR(1) forecasts; dot-dashed lines for IP growth are the TS2 recursive forecast, for inflation rate the TS3 Rolling 60m forecast, and for interest rate AR Rolling 60m forecasts, respectively. 
Figure 4. Plots of the realized data with LAR and CMRC forecasts
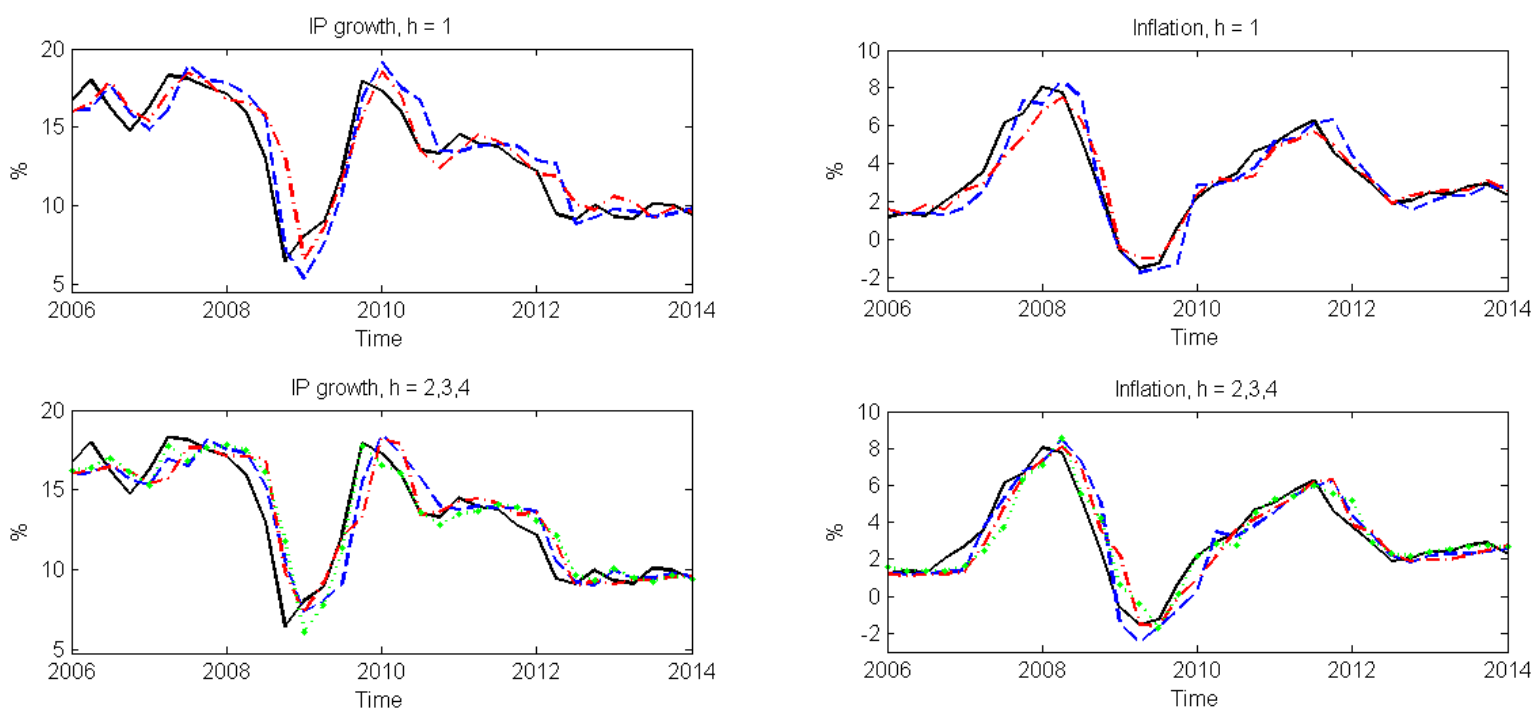

Notes:

1) In the first row about the IP growth and inflation rate, the solid lines indicate the actual data; dashed lines are the 1-quarter horizon LAR forecasts; dot-dashed lines are the CMRC survey forecasts.

2) In the second row about the IP growth and inflation rate, the solid lines indicate the actual data; dashed lines are the 2-quarter horizon LAR forecasts; dot-dashed lines are the 3-quarter horizon LAR forecasts; dotted lines are the 4-quarter horizon LAR forecasts. 
Figure 5. Parameter evolution in the LAR Model
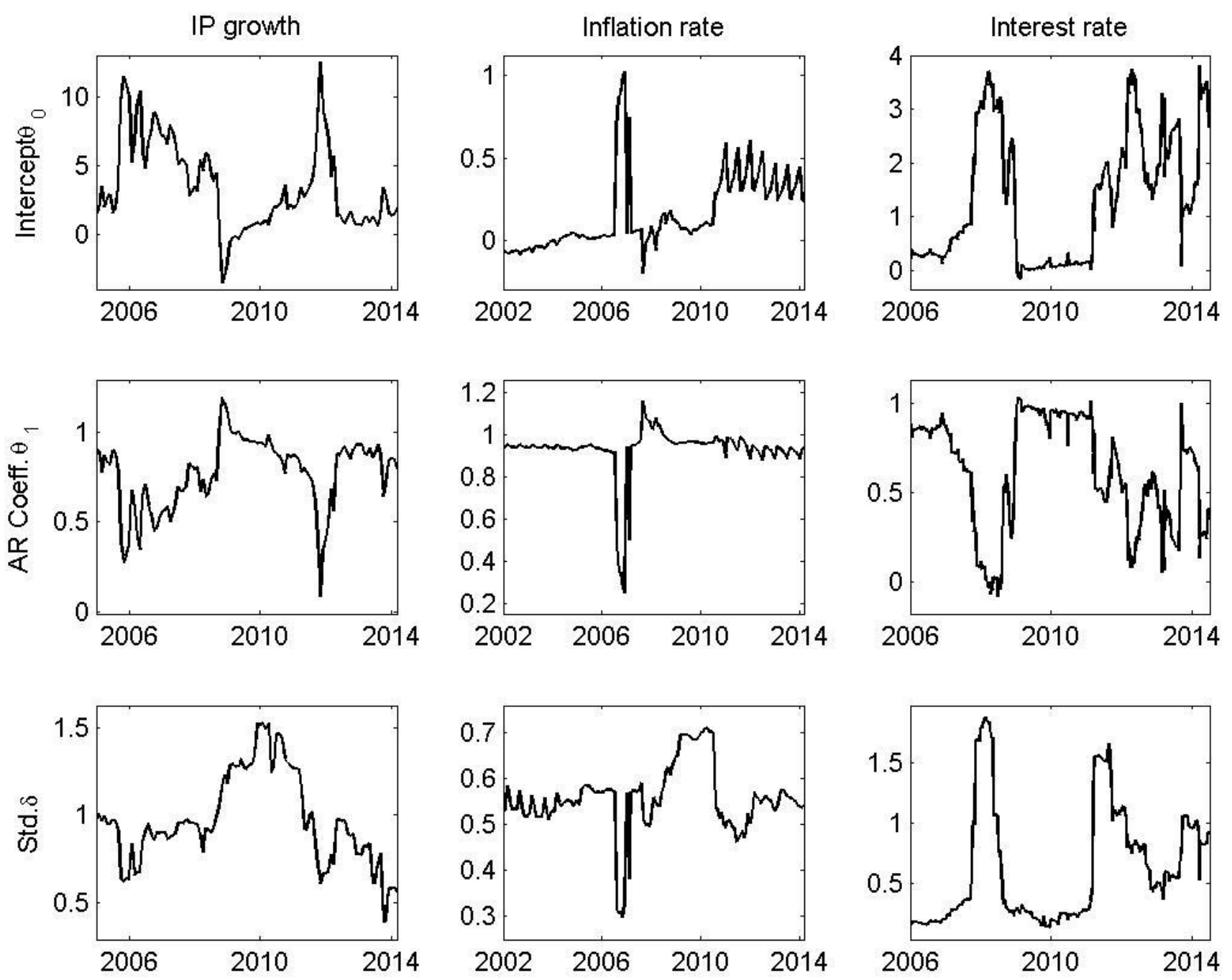

Notes: In each column, we plot the time evolution of the estimated coefficients for the LAR(1) model for $\mathrm{h}=1$ of each variables. The first row displays the intercept; the second row is the autoregressive coefficient on the lagged factor; the bottom row is the standard deviation of the error term. 
Figure 6. Detected subsamples of homogeneity
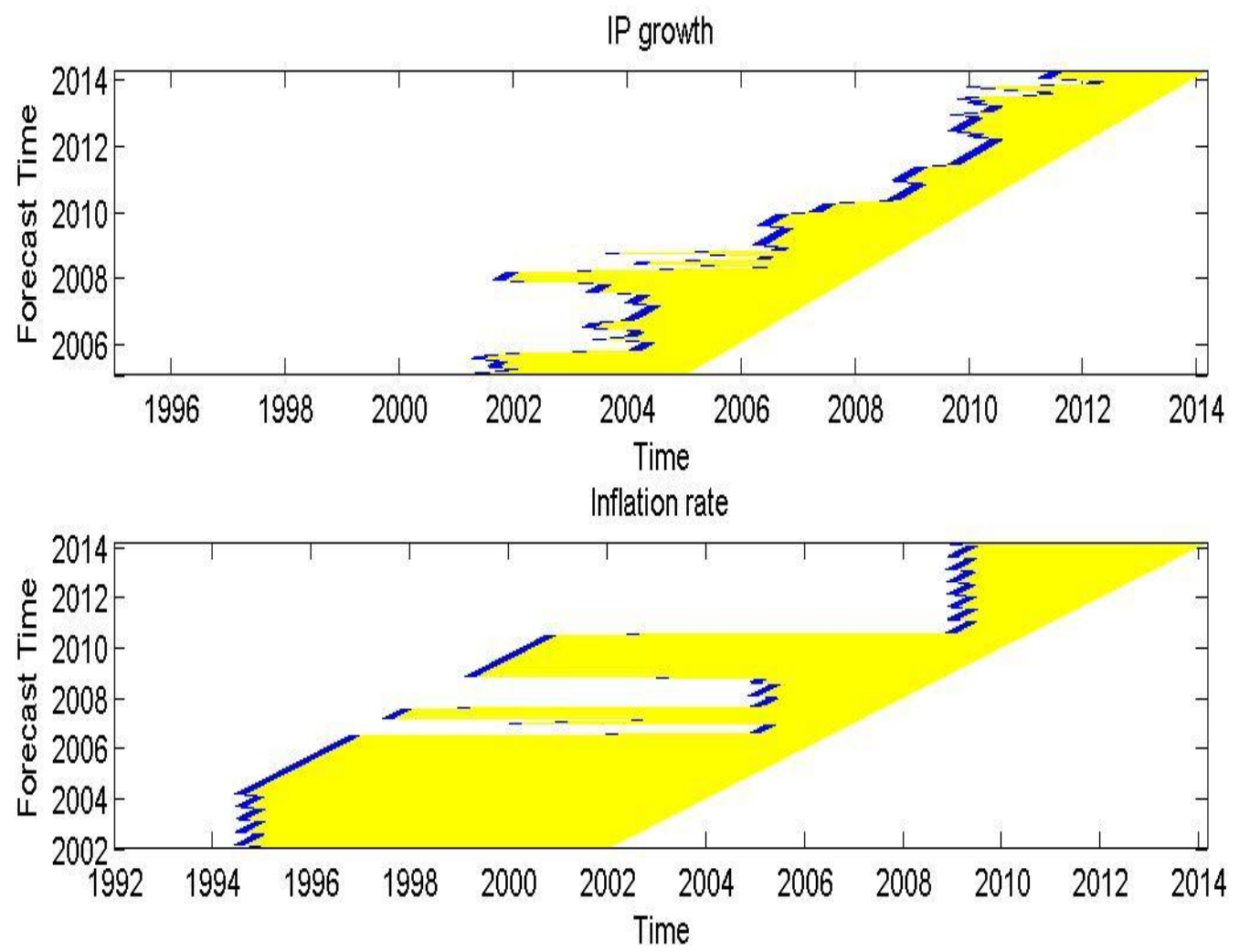

Interest rate

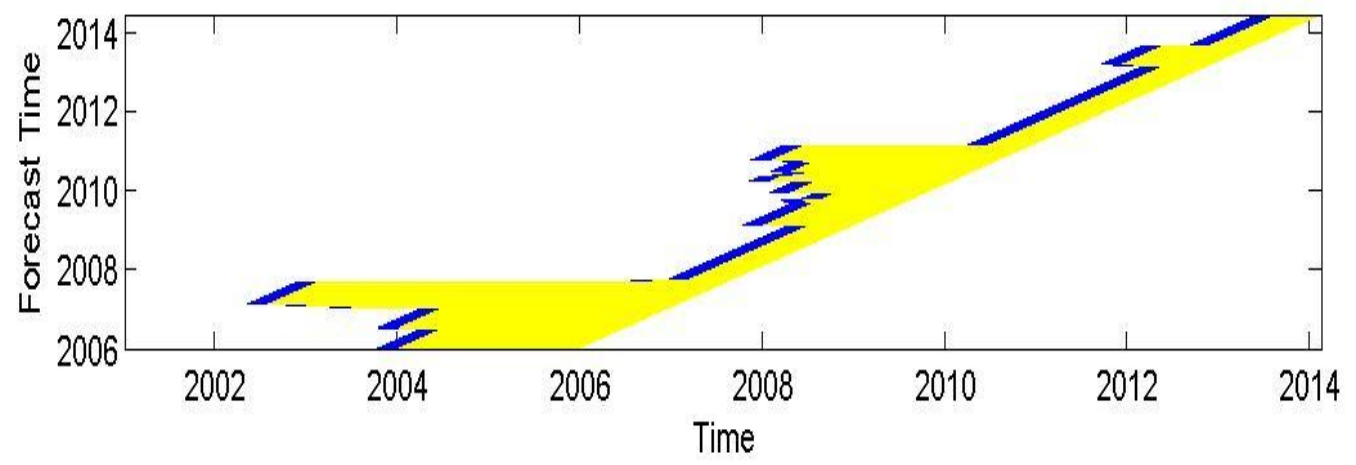

Notes: The vertical axis marks the time when the estimation and forecast is made. The selected stable sample interval is marked horizontally as a light solid line, which then decks together to form the light colored area. The dark line marks the 6-month interval during which the most recent break is detected, which then decks together to outline the boundaries of the homogeneous intervals along time. 


\section{SFB 649 Discussion Paper Series 2015}

For a complete list of Discussion Papers published by the SFB 649, please visit http://sfb649.wiwi.hu-berlin.de.

001 "Pricing Kernel Modeling" by Denis Belomestny, Shujie Ma and Wolfgang Karl Härdle, January 2015.

002 "Estimating the Value of Urban Green Space: A hedonic Pricing Analysis of the Housing Market in Cologne, Germany" by Jens Kolbe and Henry Wüstemann, January 2015.

003 "Identifying Berlin's land value map using Adaptive Weights Smoothing" by Jens Kolbe, Rainer Schulz, Martin Wersing and Axel Werwatz, January 2015.

004 "Efficiency of Wind Power Production and its Determinants" by Simone Pieralli, Matthias Ritter and Martin Odening, January 2015.

005 "Distillation of News Flow into Analysis of Stock Reactions" by Junni L. Zhang, Wolfgang K. Härdle, Cathy Y. Chen and Elisabeth Bommes, January 2015.

006 "Cognitive Bubbles" by Ciril Bosch-Rosay, Thomas Meissnerz and Antoni Bosch-Domènech, February 2015.

007 "Stochastic Population Analysis: A Functional Data Approach" by Lei Fang and Wolfgang K. Härdle, February 2015.

008 "Nonparametric change-point analysis of volatility" by Markus Bibinger, Moritz Jirak and Mathias Vetter, February 2015.

009 "From Galloping Inflation to Price Stability in Steps: Israel 1985-2013" by Rafi Melnick and till Strohsal, February 2015.

010 "Estimation of NAIRU with Inflation Expectation Data" by Wei Cui, Wolfgang K. Härdle and Weining Wang, February 2015.

011 "Competitors In Merger Control: Shall They Be Merely Heard Or Also Listened To?" by Thomas Giebe and Miyu Lee, February 2015.

012 "The Impact of Credit Default Swap Trading on Loan Syndication" by Daniel Streitz, March 2015.

013 "Pitfalls and Perils of Financial Innovation: The Use of CDS by Corporate Bond Funds" by Tim Adam and Andre Guettler, March 2015.

014 "Generalized Exogenous Processes in DSGE: A Bayesian Approach" by Alexander Meyer-Gohde and Daniel Neuhoff, March 2015.

015 "Structural Vector Autoregressions with Heteroskedasticy" by Helmut Lütkepohl and Aleksei Netšunajev, March 2015.

016 "Testing Missing at Random using Instrumental Variables" by Christoph Breunig, March 2015.

017 "Loss Potential and Disclosures Related to Credit Derivatives - A CrossCountry Comparison of Corporate Bond Funds under U.S. and German Regulation" by Dominika Paula Gałkiewicz, March 2015.

018 "Manager Characteristics and Credit Derivative Use by U.S. Corporate Bond Funds" by Dominika Paula Gałkiewicz, March 2015.

019 "Measuring Connectedness of Euro Area Sovereign Risk" by Rebekka Gätjen Melanie Schienle, April 2015.

020 "Is There an Asymmetric Impact of Housing on Output?" by Tsung-Hsien Michael Lee and Wenjuan Chen, April 2015.

021 "Characterizing the Financial Cycle: Evidence from a Frequency Domain Analysis" by Till Strohsal, Christian R. Proaño and Jürgen Wolters, April 2015.

\section{SFB 649, Spandauer Straße 1, D-10178 Berlin http://sfb649.wiwi.hu-berlin.de}




\section{SFB 649 Discussion Paper Series 2015}

For a complete list of Discussion Papers published by the SFB 649, please visit http://sfb649.wiwi.hu-berlin.de.

022 "Risk Related Brain Regions Detected with 3D Image FPCA" by Ying Chen, Wolfgang K. Härdle, He Qiang and Piotr Majer, April 2015.

022 "An Adaptive Approach to Forecasting Three Key Macroeconomic Variables for Transitional China" by Linlin Niu, Xiu Xu and Ying Chen, April 2015. 